\title{
التسامح الديني في الاسلام و أثره على السلم الاجتماعي
}

Doi: $10.23918 /$ ilic2020.14

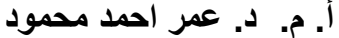 \\ جامعة السليمانية/ كلية العلوم الإسلامية/ قسم الثريعة}

Email:omerrangena57@gmail.com

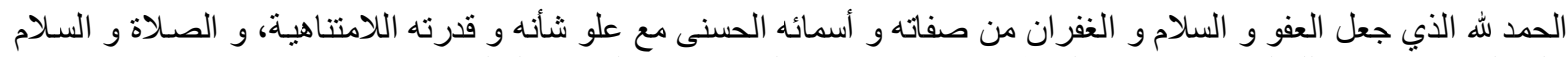

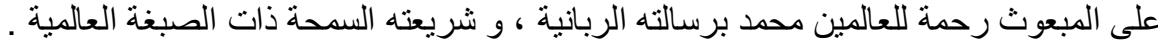

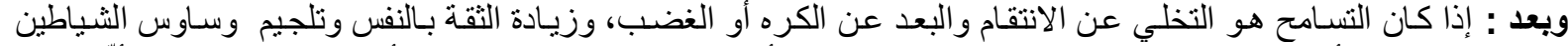

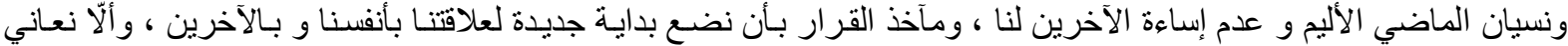

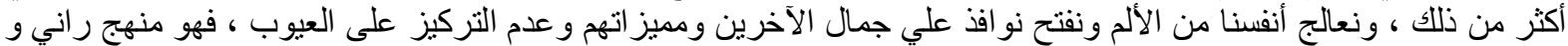

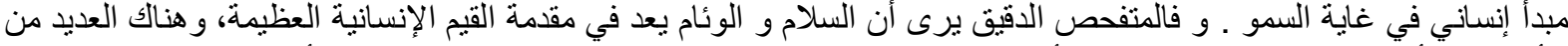

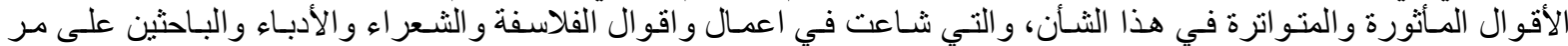

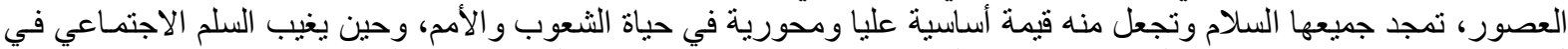

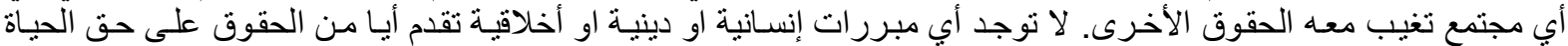

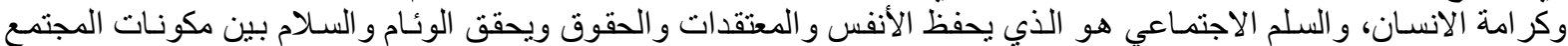

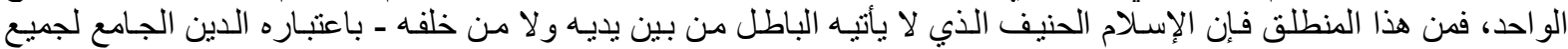

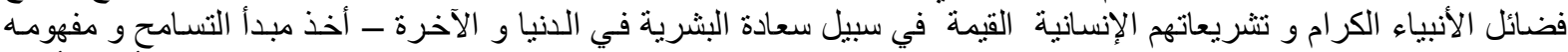

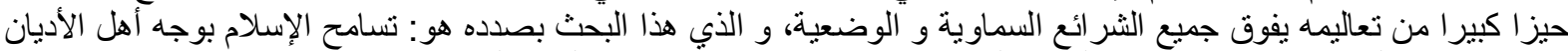

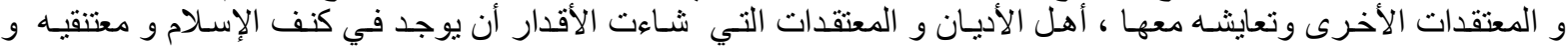

بوجوارهو جانبه.

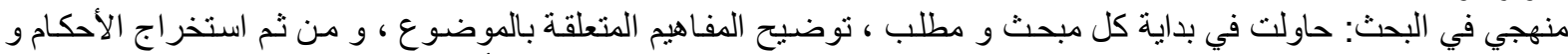

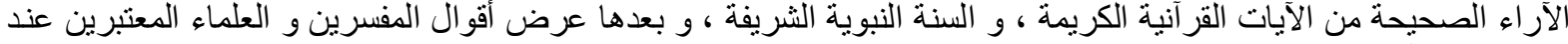

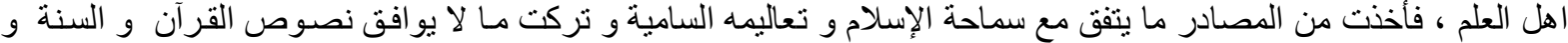

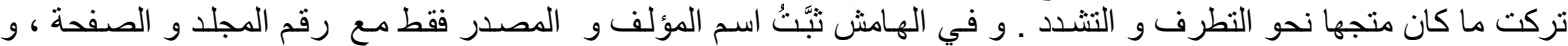

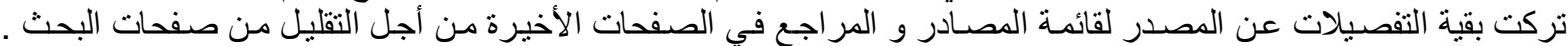

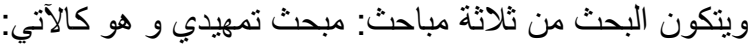

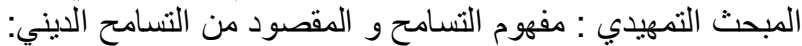

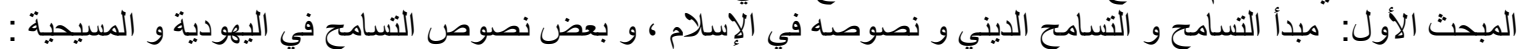

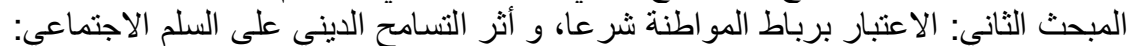

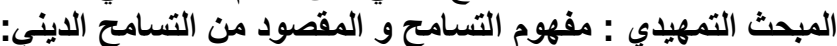

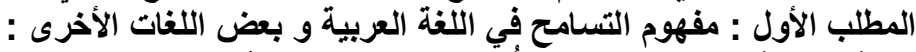

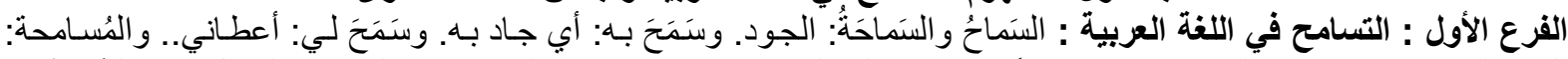

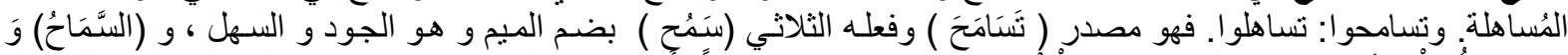

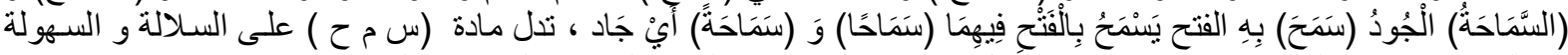

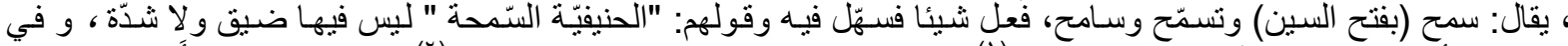

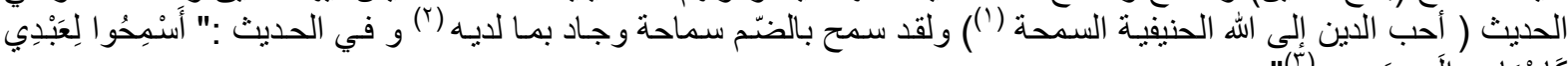

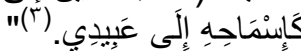

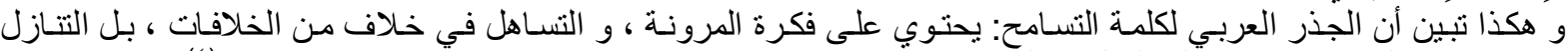

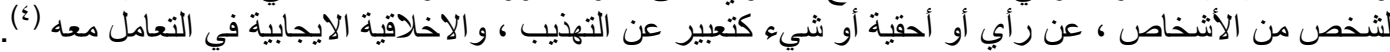

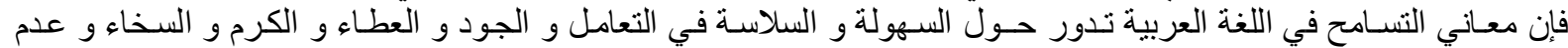

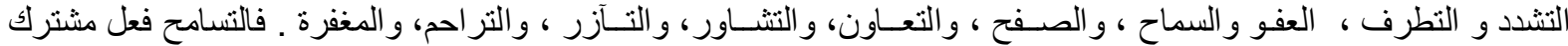

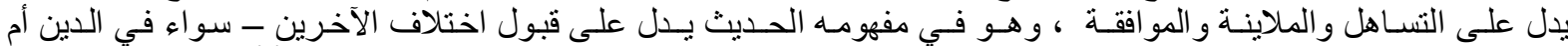
العرق أم السياسة ــ أو عدم منع الآخرين مـن أن يكونو الخرين مفين أو عدم إكر اههم على التخلي عن آخريتهم (0).

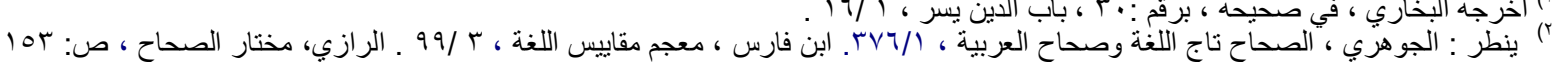

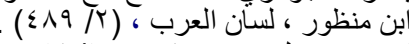

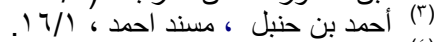

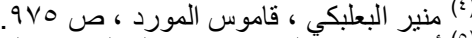

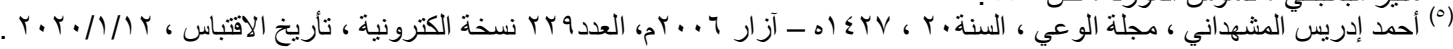


الفرع الثاني : جذور التسامح و مصطلحه في بعض اللغات الغربية وفي اللاتينية :

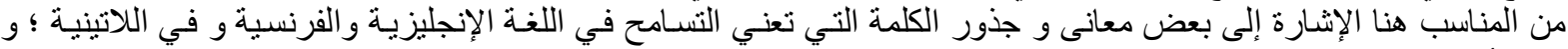

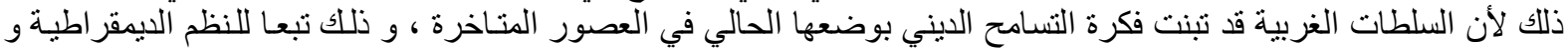

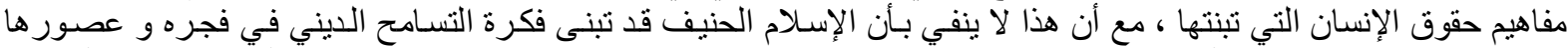

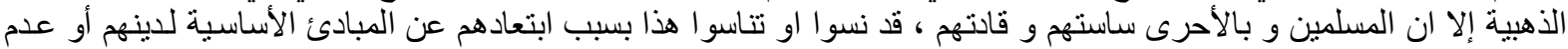

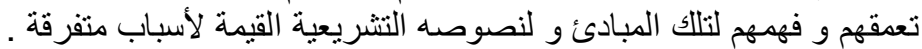

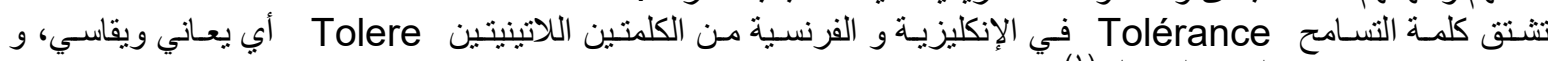
Tolerantia

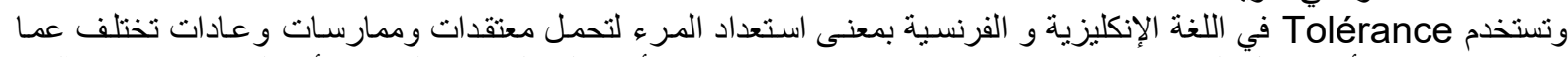

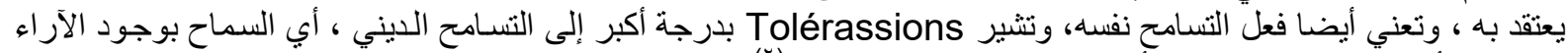

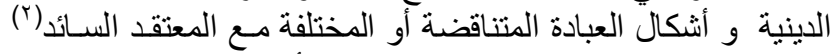

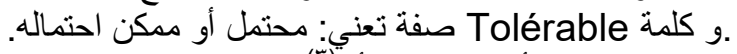

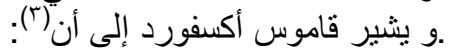

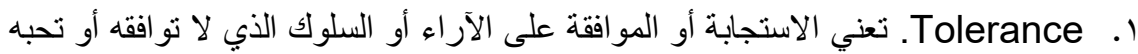

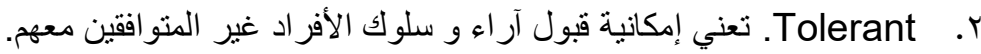

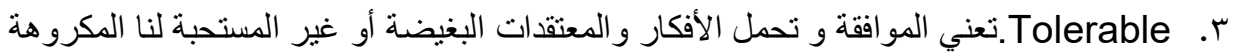

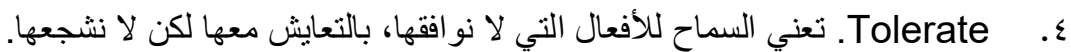

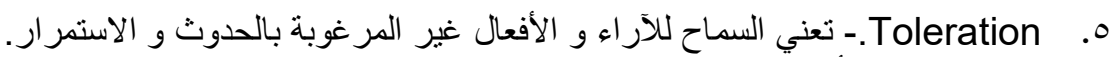
و يقول قـاموس "المورد" أن هذه الكلمة تعني :

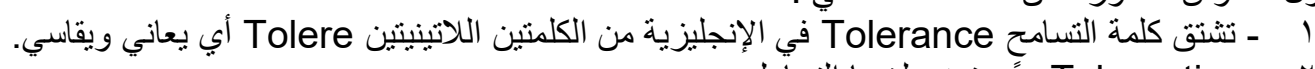
Tolerantia - r

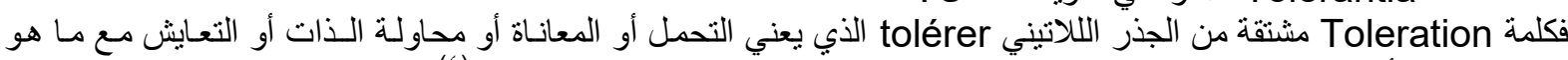

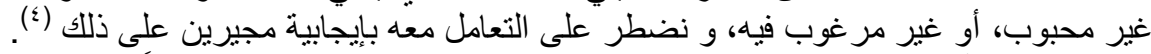

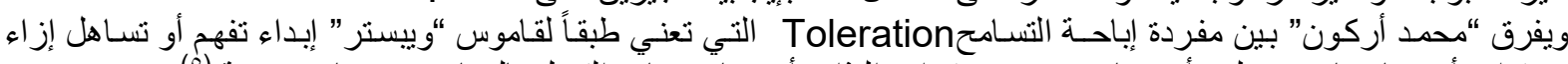

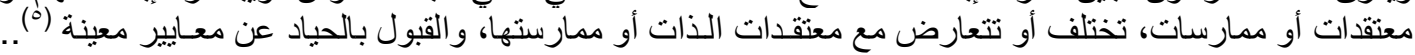

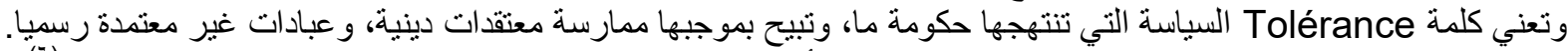

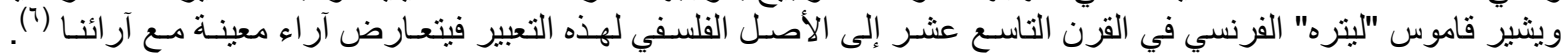

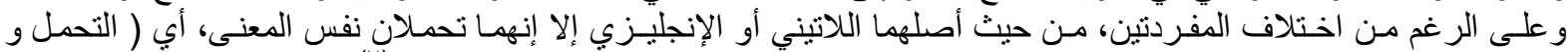

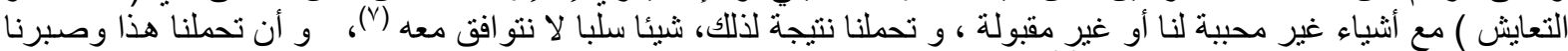

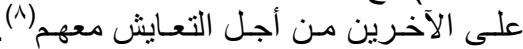

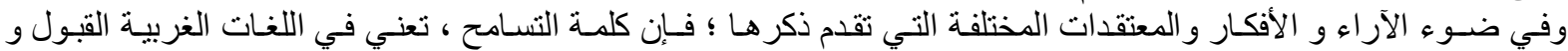

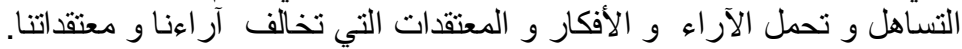

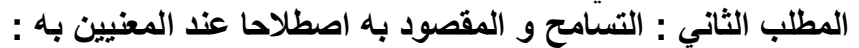

هناك تعاريف مختلفة لمفهوم التسامح عند الباحثين المعنيين بالتسامح من أهل العلم فنورد بعضا من هذه : التعاريف قدر تعلقها بالبحث هذا : نواريف

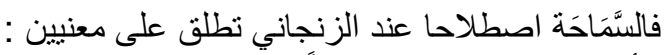
الأول: (بذل ما لا يجب تفضاًلً ) ).

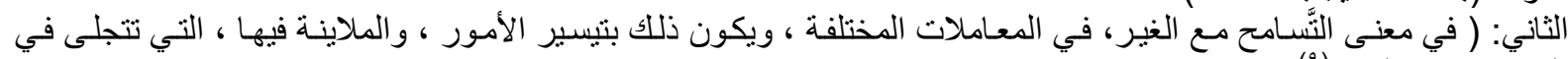

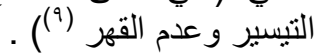

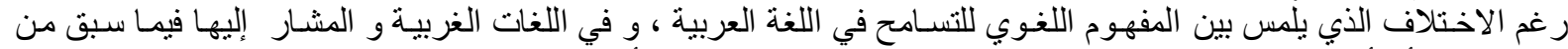

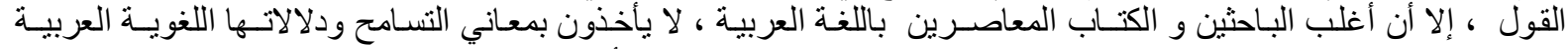

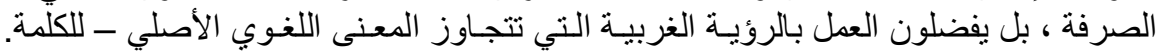

(') عصام عبداله ، المقومات الفلسفية للتسامح الثقافي، الأمارات العربية ، د.ت ، صل ال.

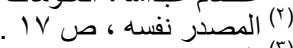

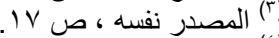

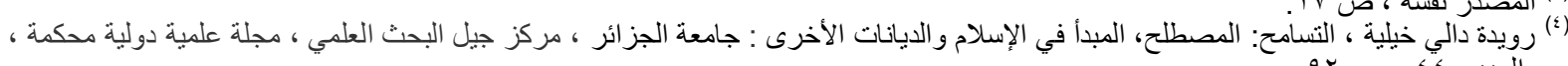

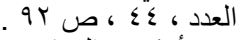

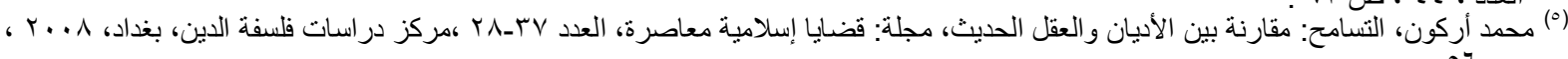
ص

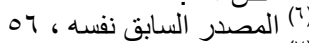

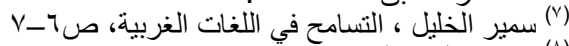

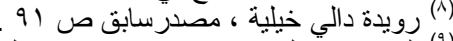

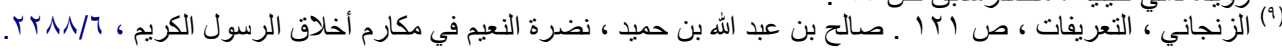


و فيما يأتي نماذج من مفهوم التسامح عند البحاثة المغنيين :

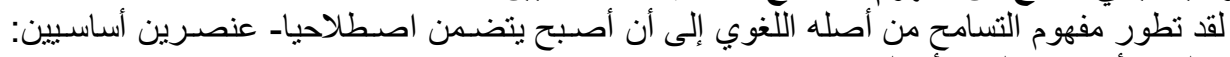

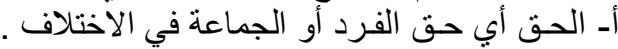

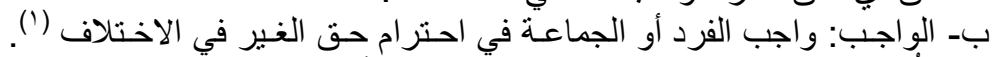

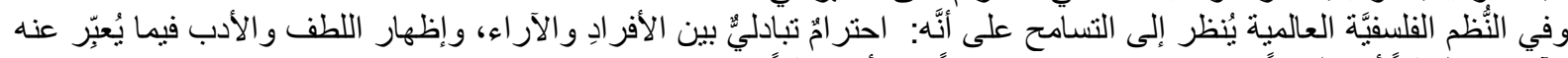

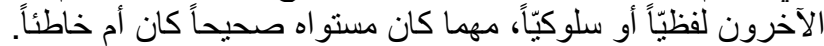

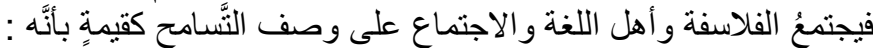

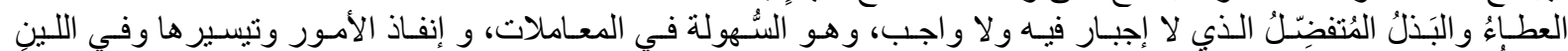
و والتلطُفْ (r).

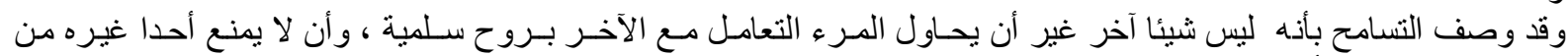

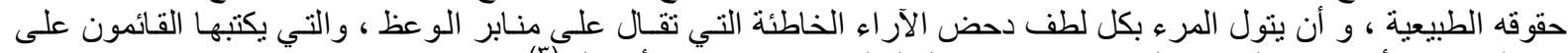

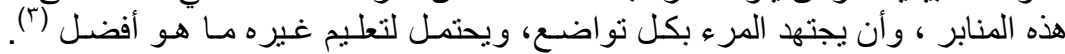

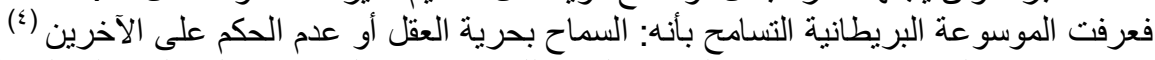

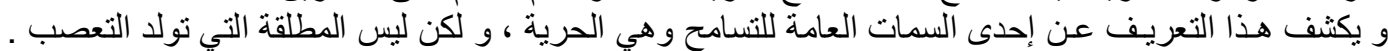

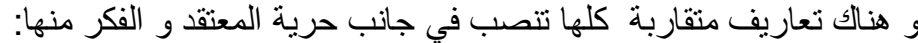

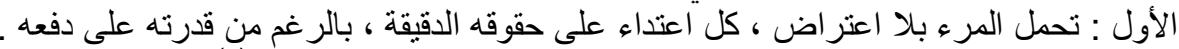

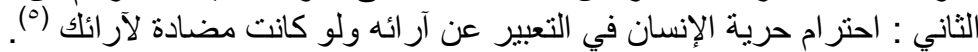

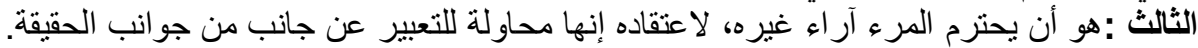

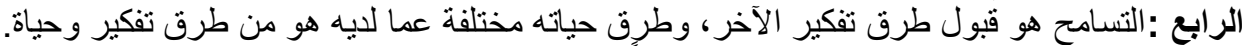

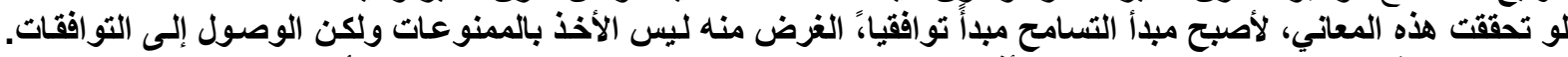

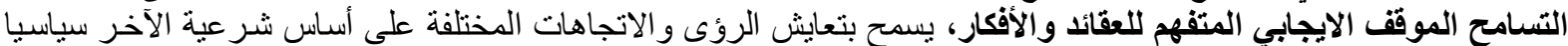

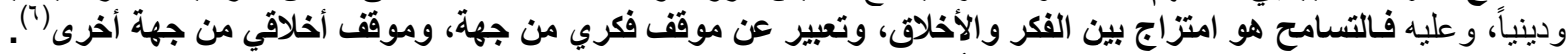

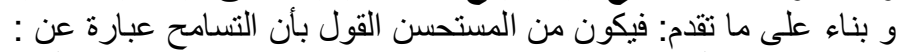

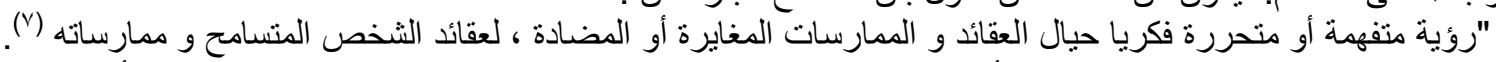

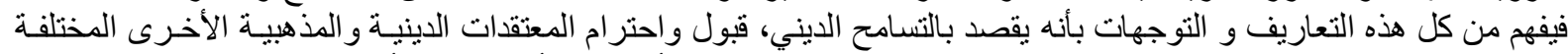

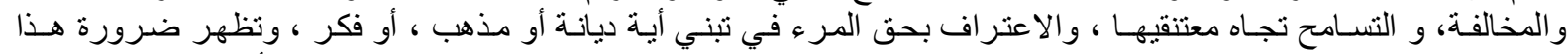

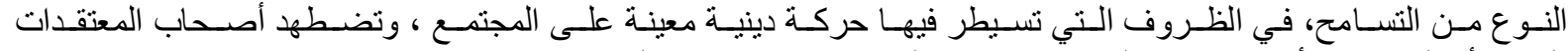

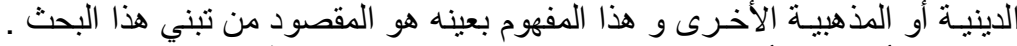

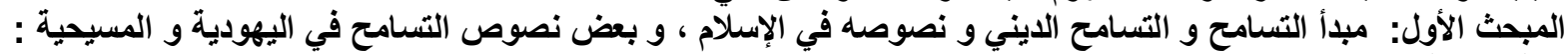

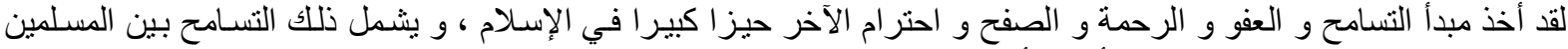

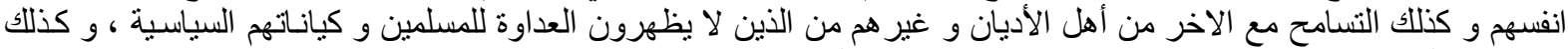

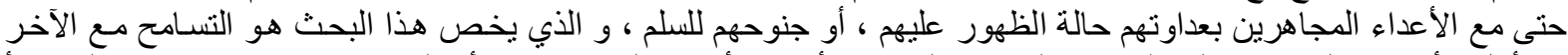

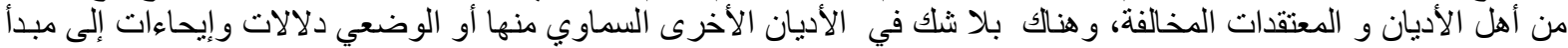

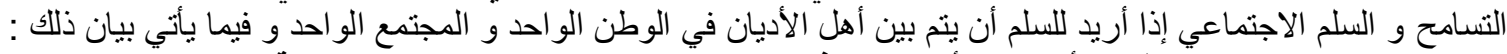

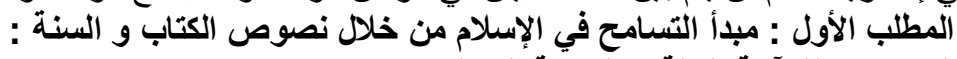

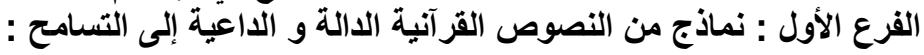

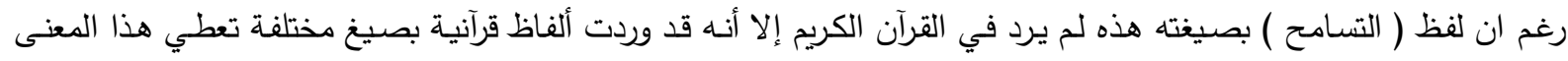
بالضبط بل و أكثر منه أحيانا:

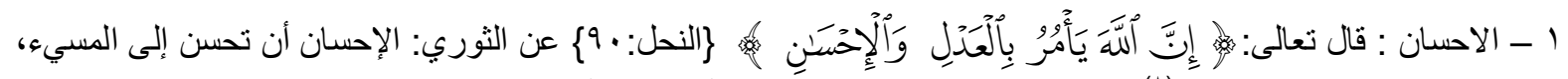

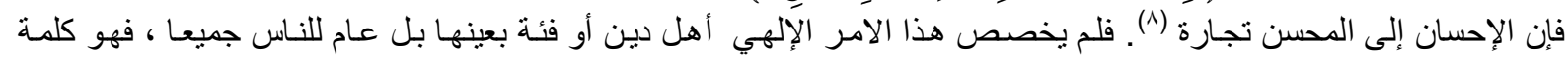

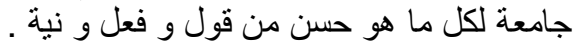

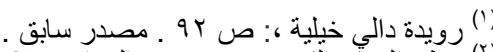

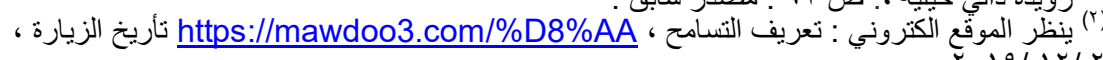

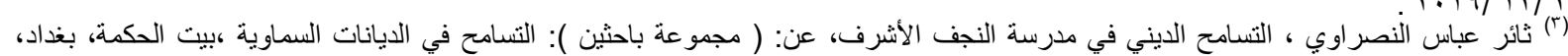

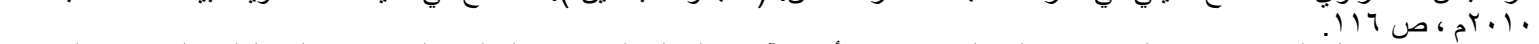
(๕) نقلا عن : حميد نفل النداوي، ثقافة التسامح وجدلية العلاقة بين الأنا والآخر، المجلة السياسية والدولية، العدد ^ ، كلية العلوم السياسية، الجامعة

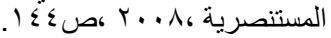

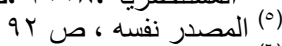

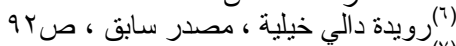

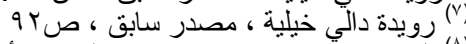

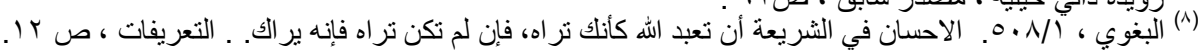




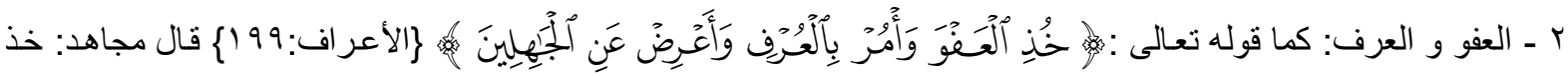

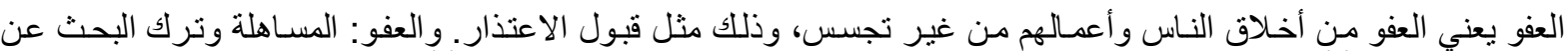

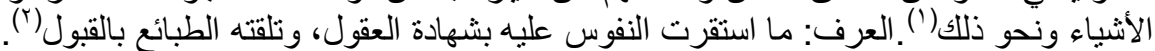

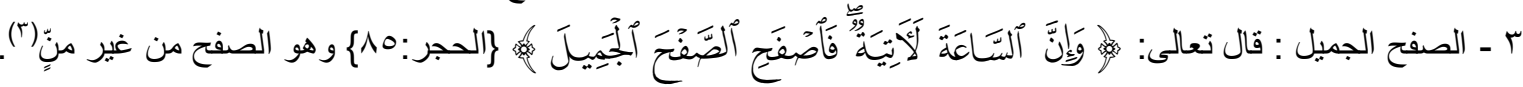

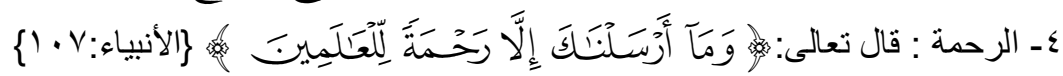

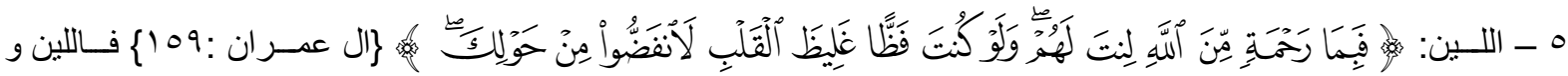

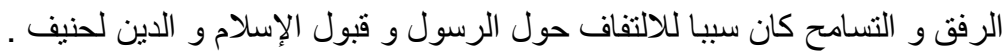

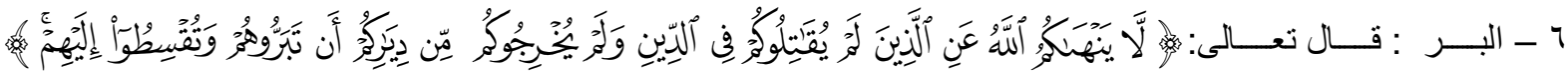

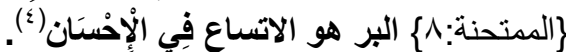

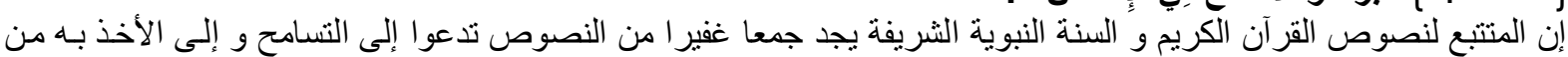

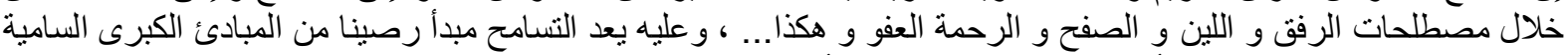

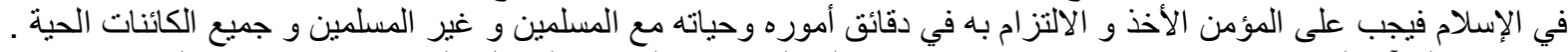

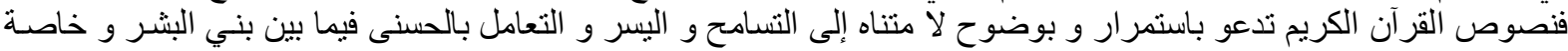
فيما يعني بالتسامح في المعتقد و الدين : بانتران

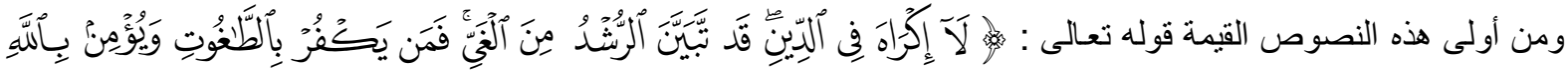

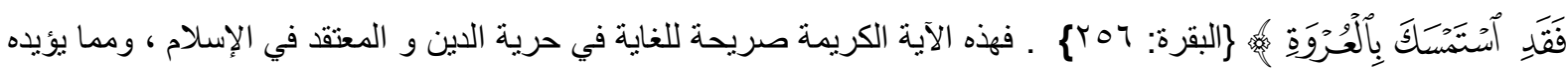

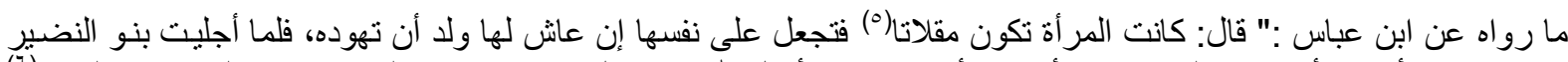

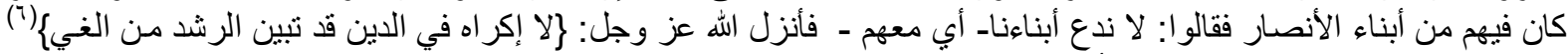

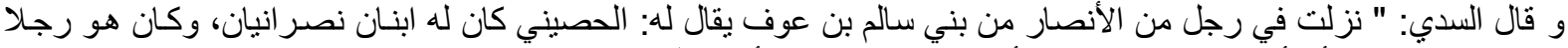

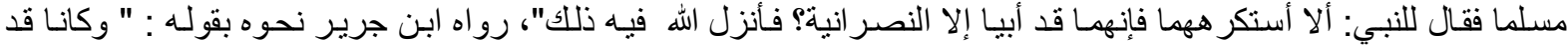

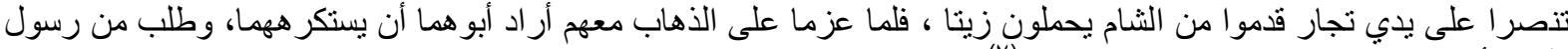
الله فهذه الروايات في سبب نزول الآنية الكريمة تؤكد حرية التنين للإنسان بشكل لا لبس في ؛ لأن الله تعالى هو الذي يفصل بين أهل

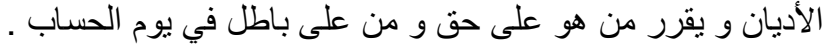

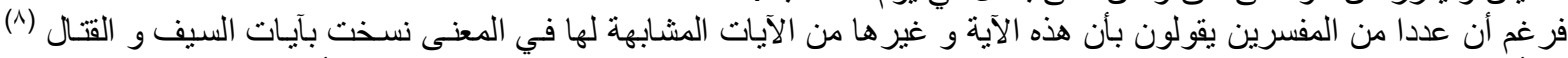

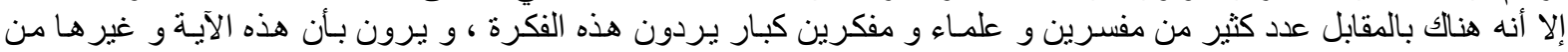

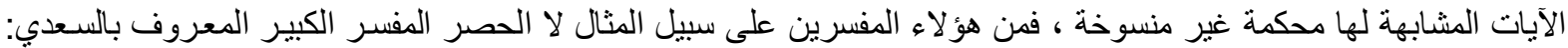

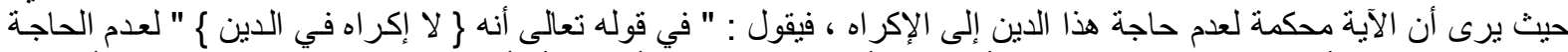

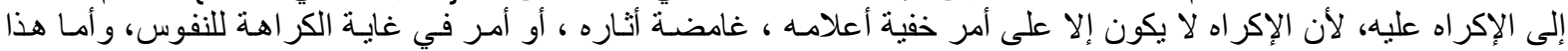

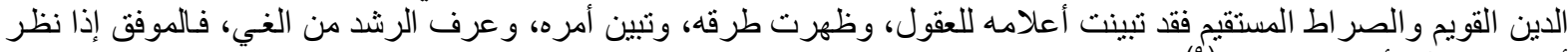

أدنى نظر إليه أثاره واختاره"(')

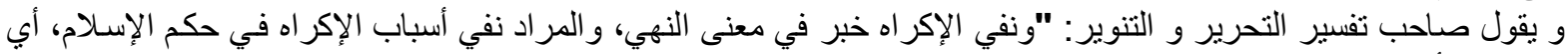

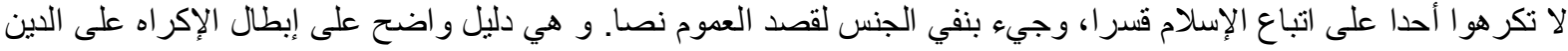

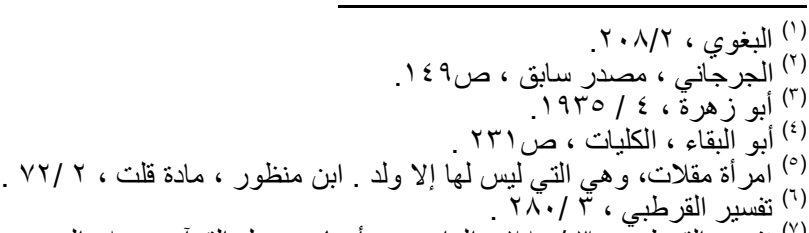

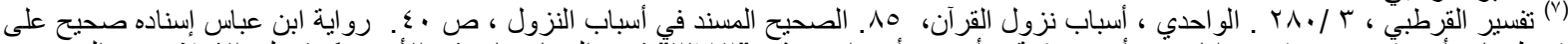

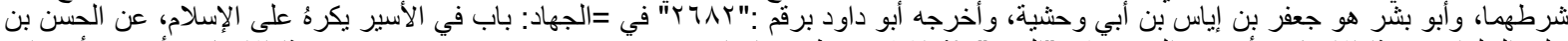

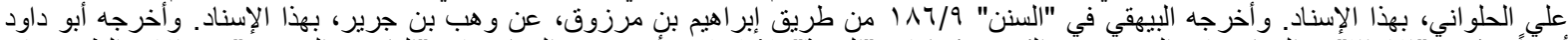

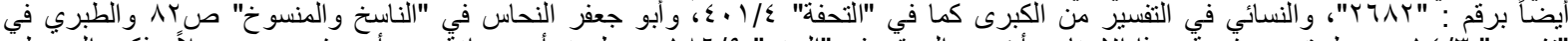

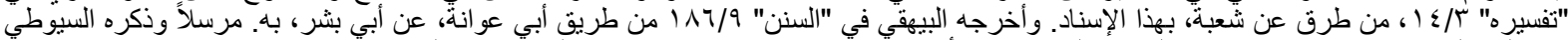

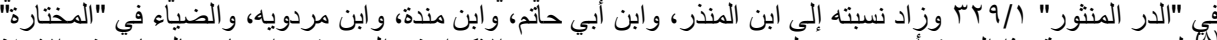

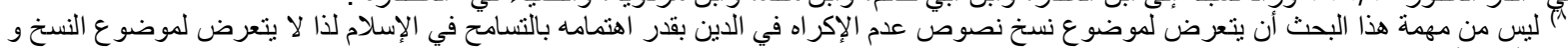


بسائر أنو اعـه، لأن أمر الإيمـان يجري على الاستدلال، و التمكين من النظر ، وبالاختيـار. فإن التز ام الدين عن إكر اه لا يأتي

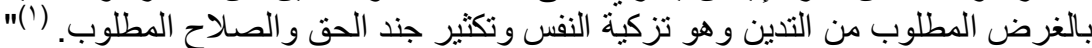

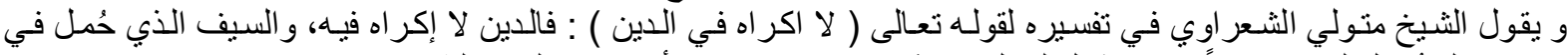

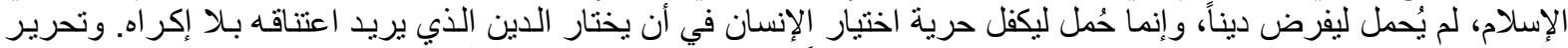

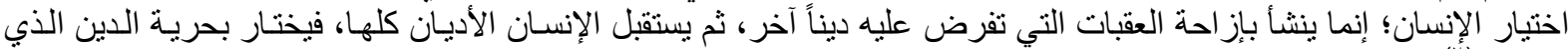

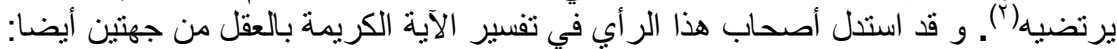

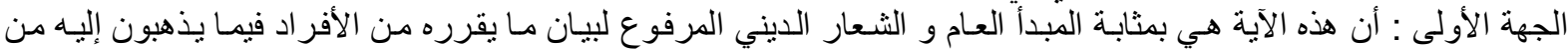

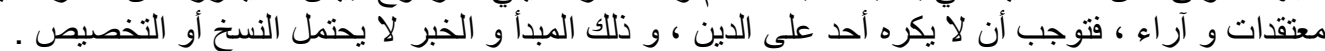

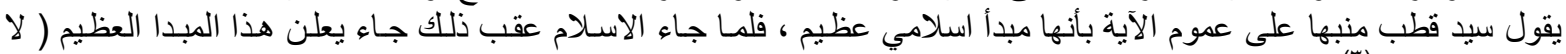
اكر اه في الدين ) آنان.

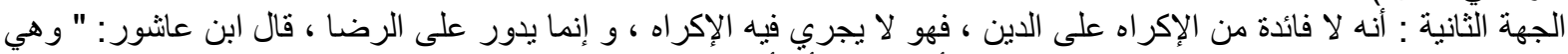

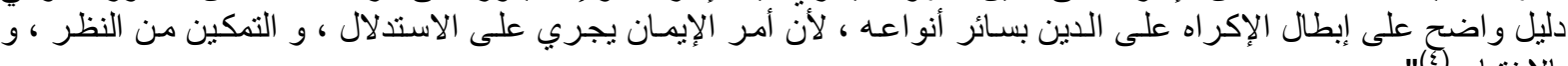
بالاختيار (ई)". و قال الإمام أبو زهرة : " هذه الآية الكريمة واضحة كما قررنا في حقيقتين ثابتتين:

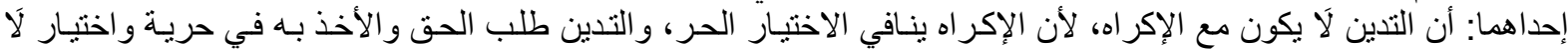
تشوبهما شائبة. الحقيقة الثانية: أن الله سبحانه وتعالى ينهى عن الإكر اه في الدين، وحمل الناس عليه بقوة السيف حتى لَا يكثر النفاق و المنافقون.

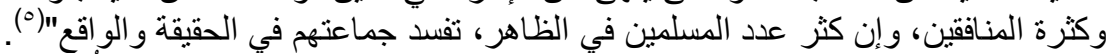

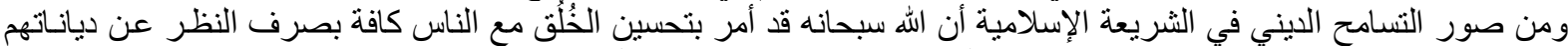

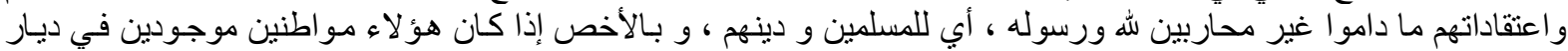

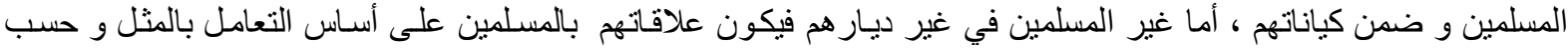

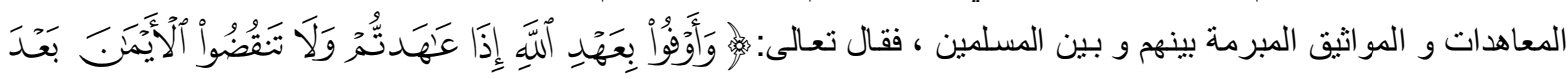

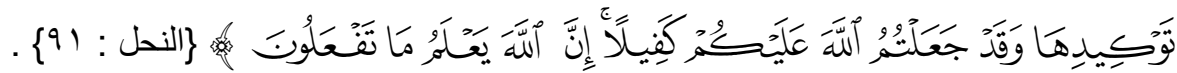

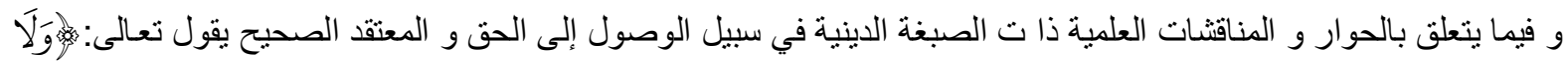

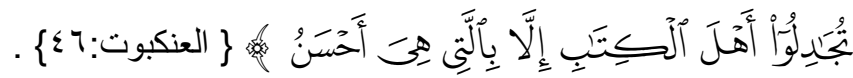

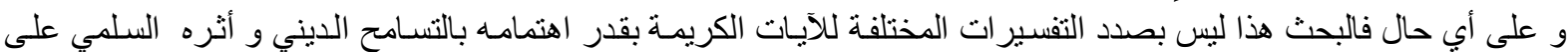

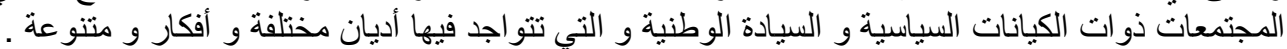

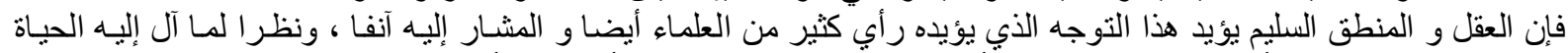

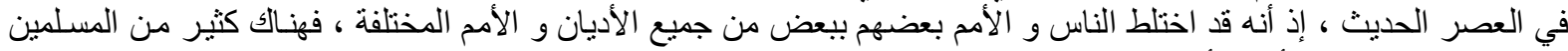

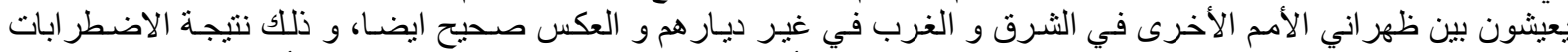

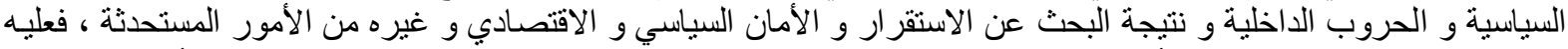

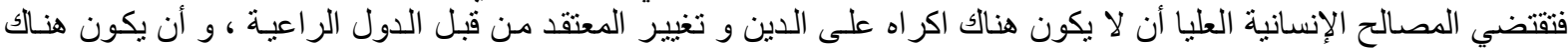

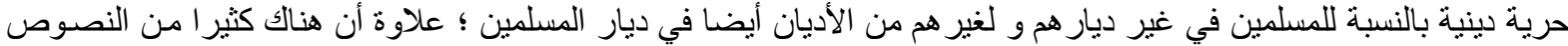
الدينية تؤيد هذا الاتجاه فمن هذه النصوص:

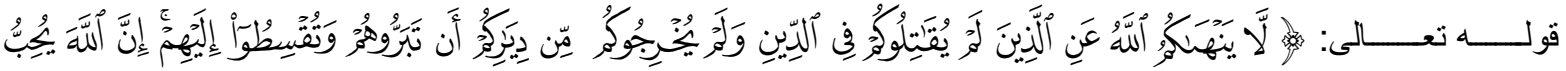

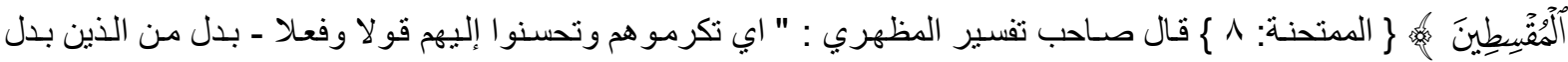

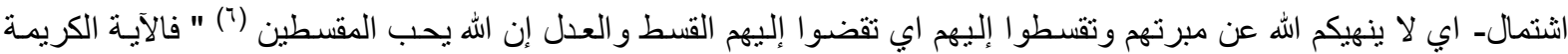

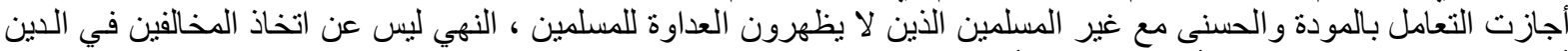

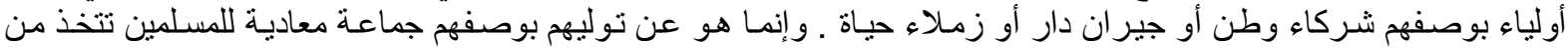

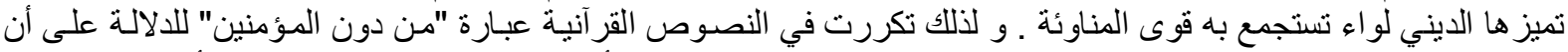

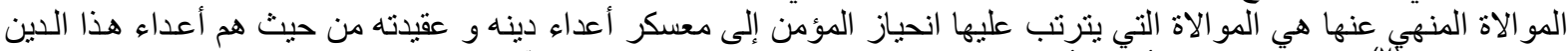

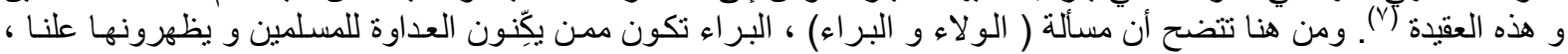

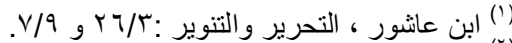

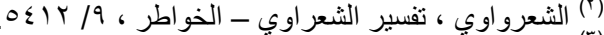

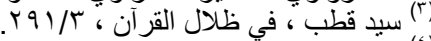

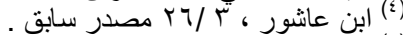

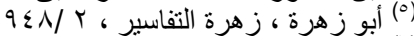

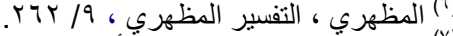

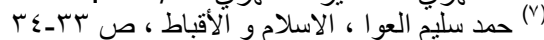




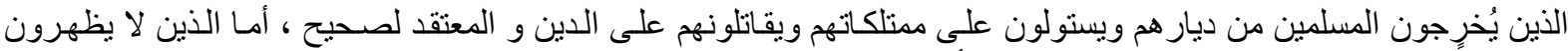

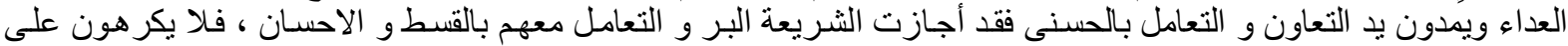

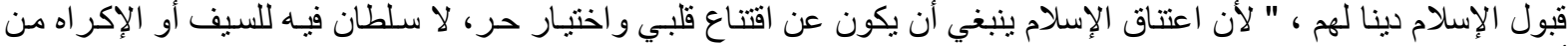

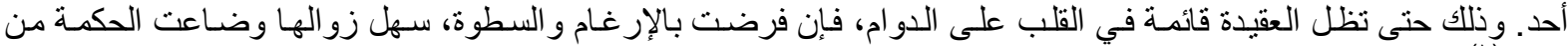
قبولها (') (')

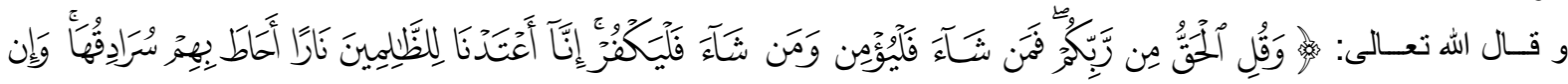

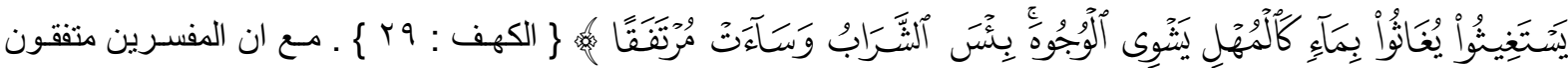

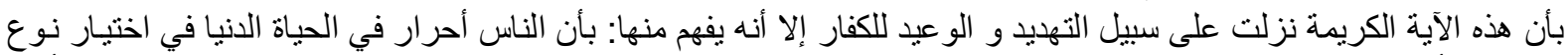

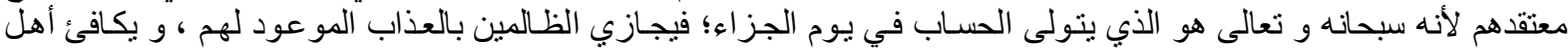

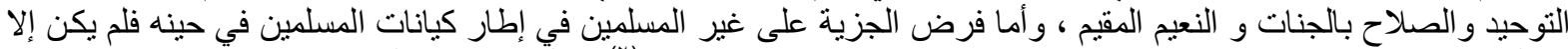

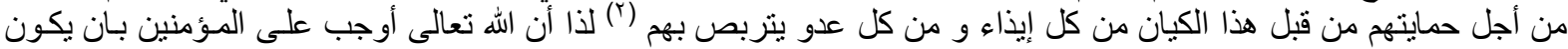

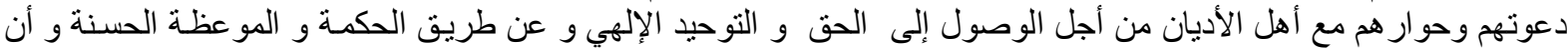

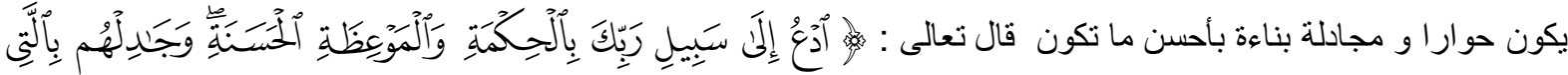

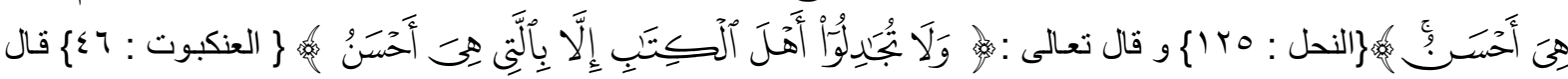

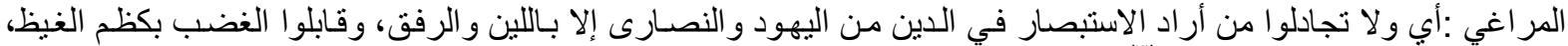

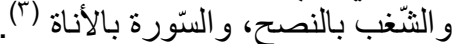
فعلاوة على هذه كلها إن الله تعالى قدأن أمر بالعفو و الصفح الجميل و التجاوز عن الأخطاء :

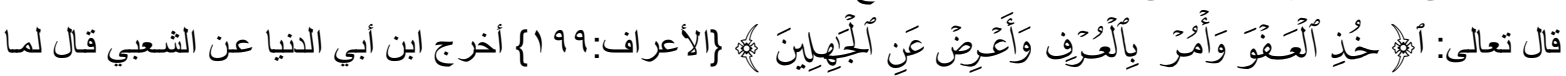

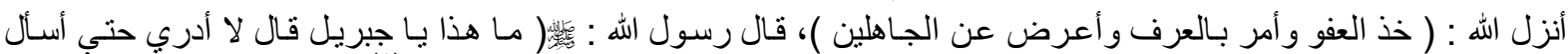

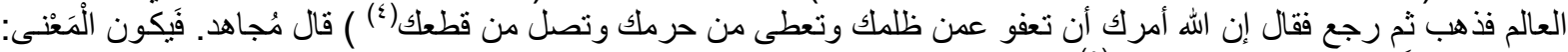

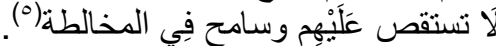

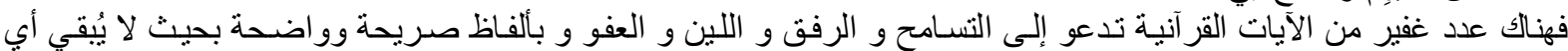

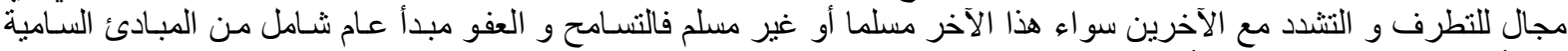

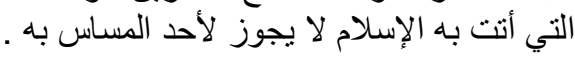

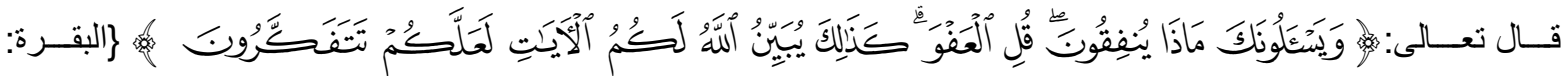

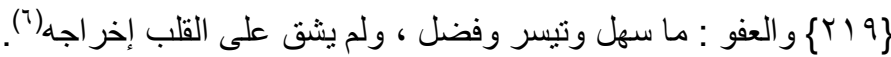

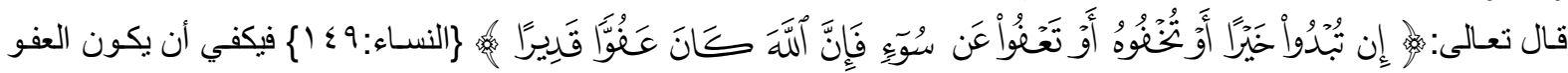

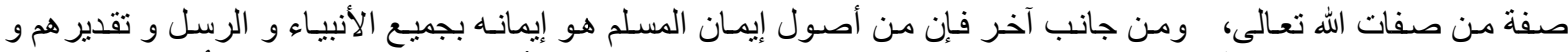

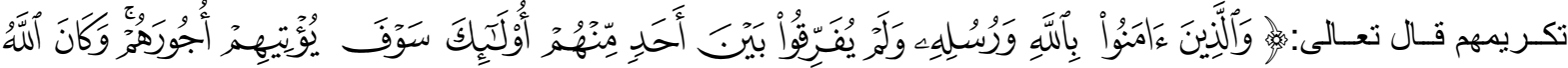

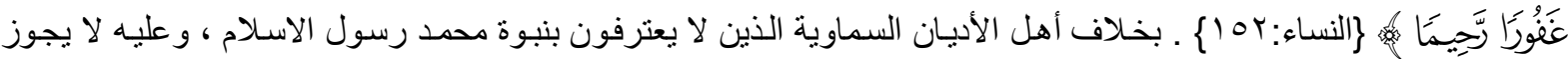
للمسلم توجيه أية إهانة او سوء كلام إلى أب نبي من أنبياء الأمم الأخرى كونهم مبعوثين من الله نعالى فهم متفقون في أصول الصول

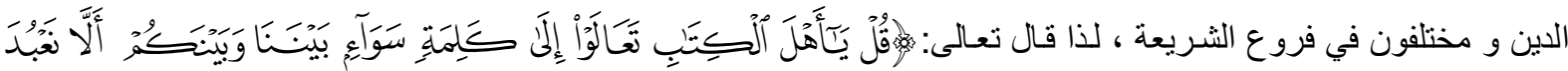

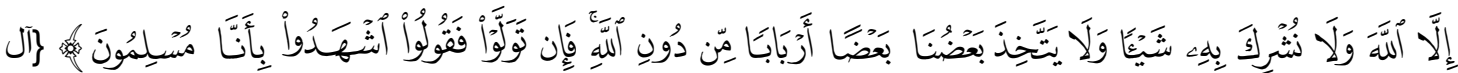
عمران: و قــــال تعـــــالى

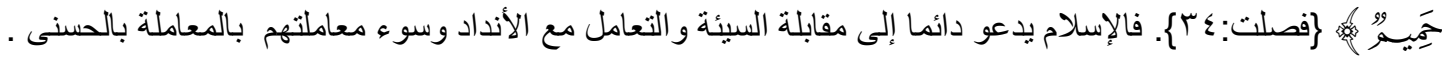

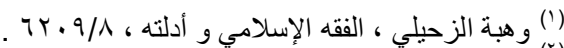

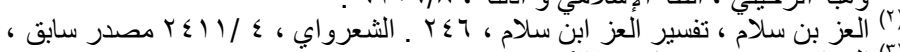

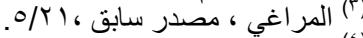

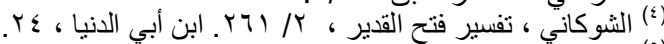

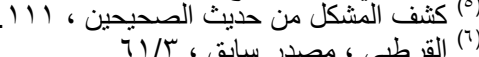


فقد أعلن الاسلام قبل أكثر من . .ـ ا سنة أعظم مبدأ انساني سام بلغ أعلى حدود التسامح بين جميع الفئات و الأعر اق و الأديان

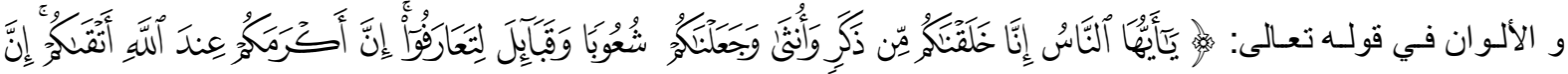

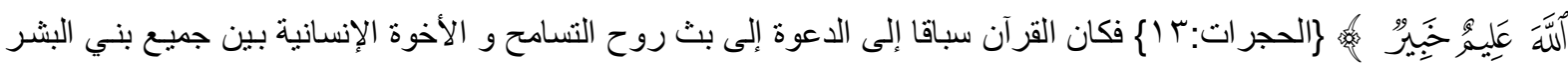

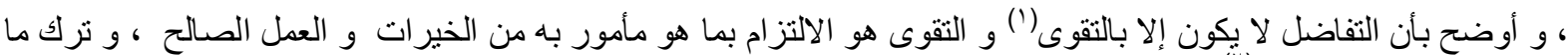

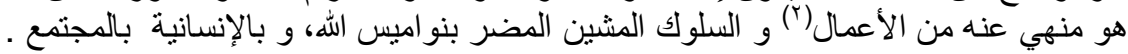

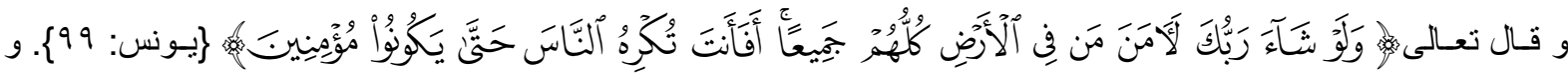

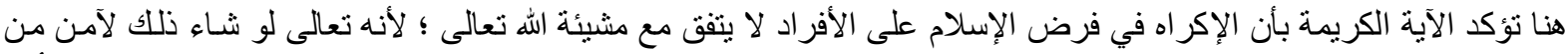

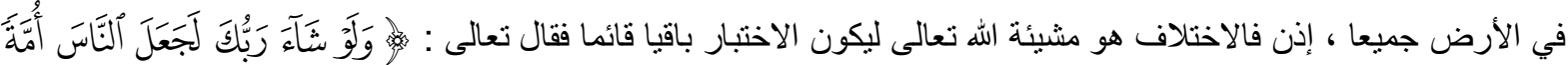

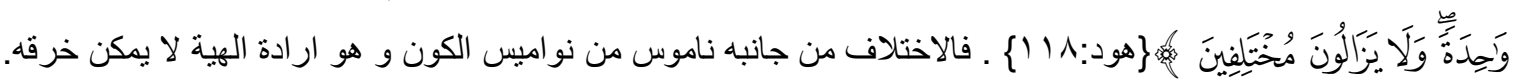

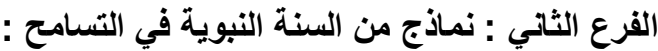

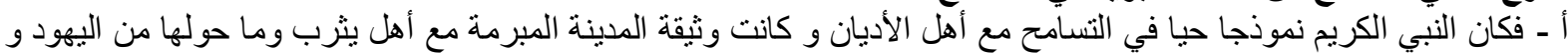

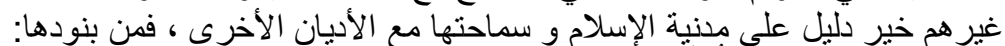

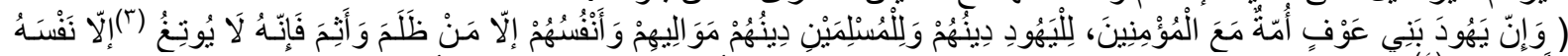

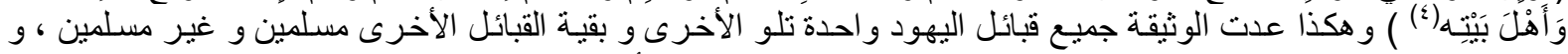

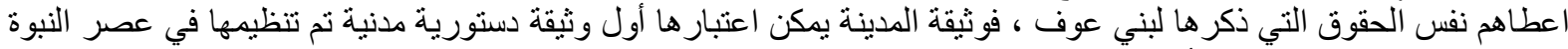

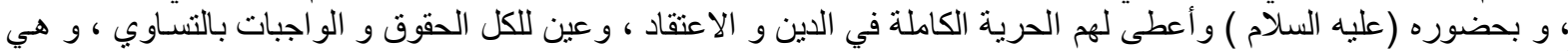

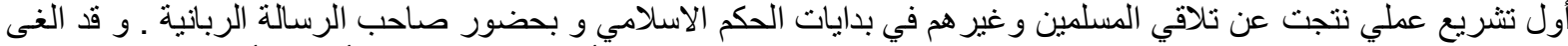

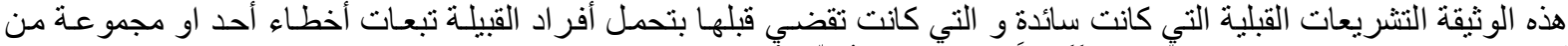

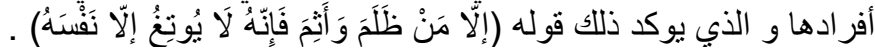

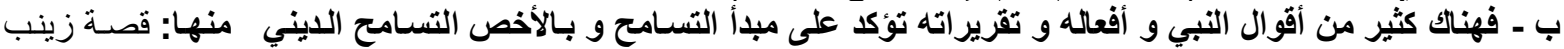

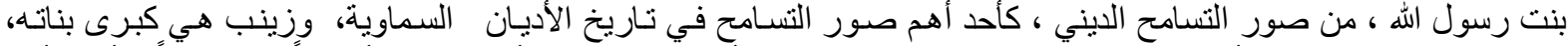

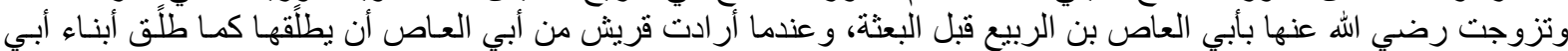

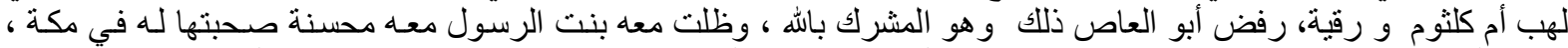

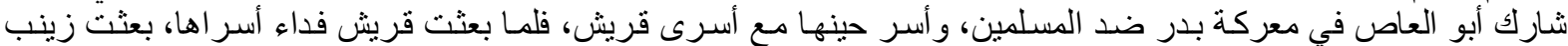

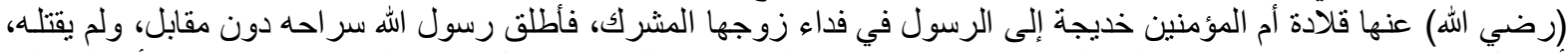

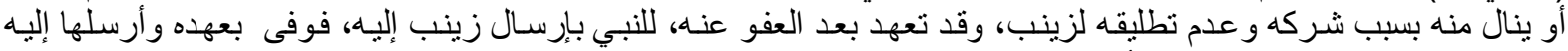

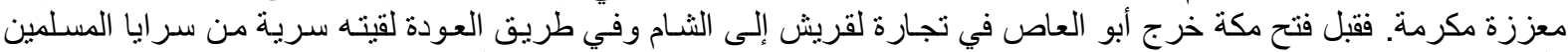

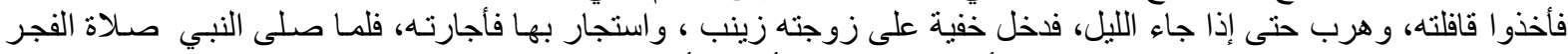

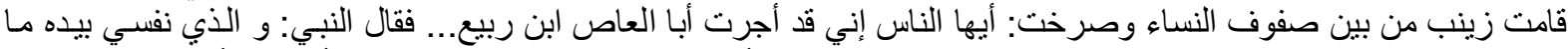

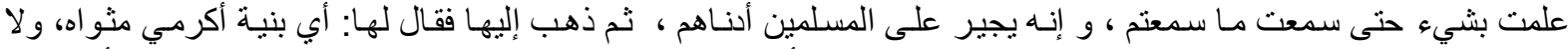

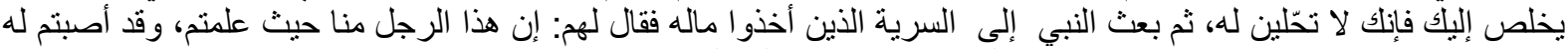

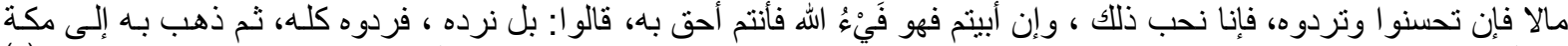

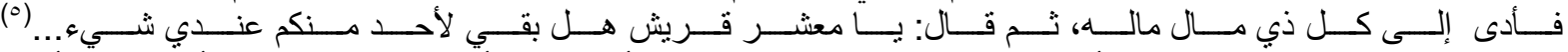

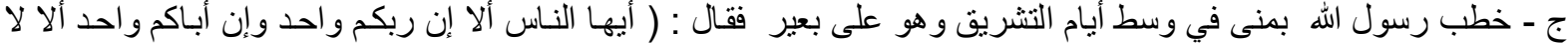

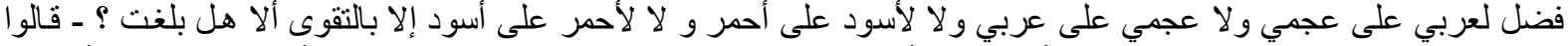

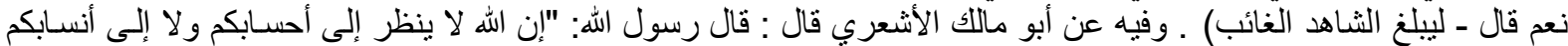

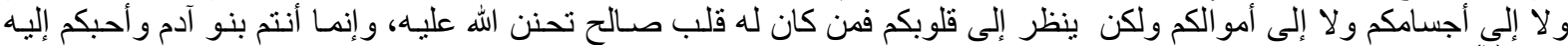

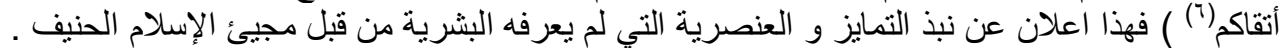

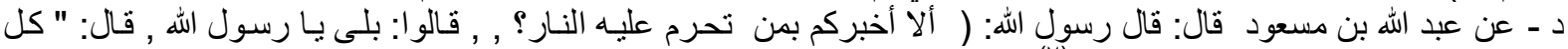

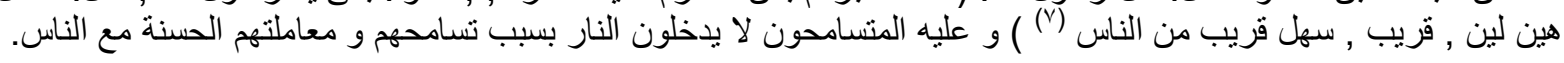

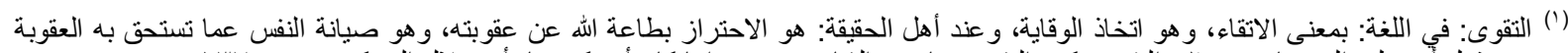

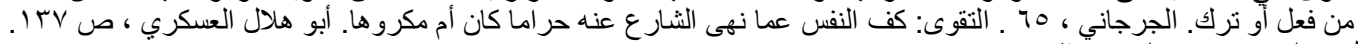

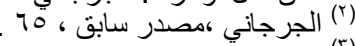

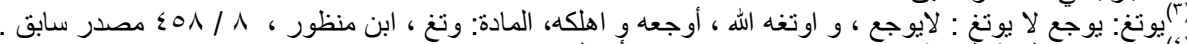

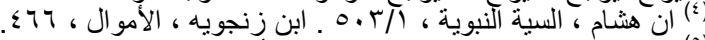

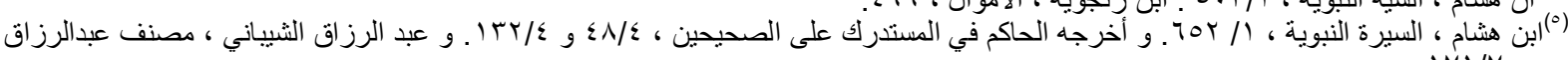
IVI/V،

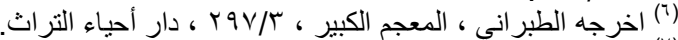

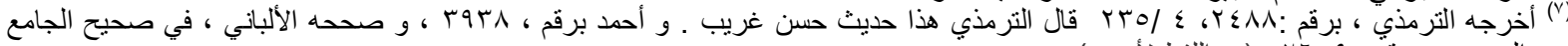

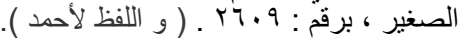




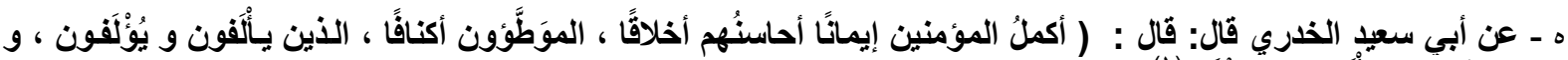

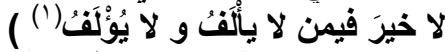
و - عن عائشة أن رسول الله: ( أن رسول الله قال: مكتوب في الإنجيل: لا فظ فو و لا لا غليظ ولا سخاب بالأسواق، و لا يجزي

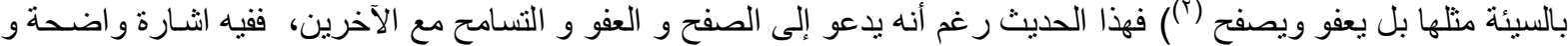

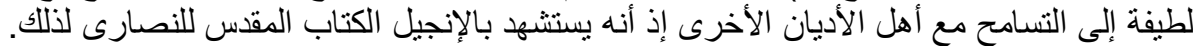

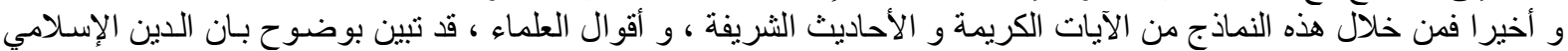

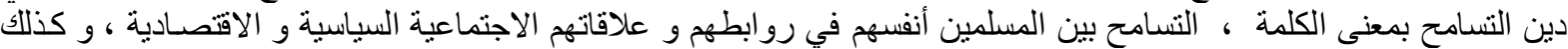

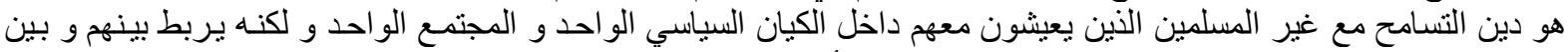

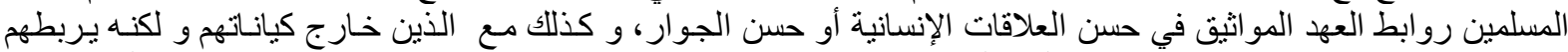

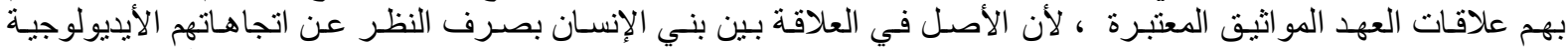
و الفكرية، هو الرحمة والإحسان والبر والقسط وتجنب الإيذاء؛ لذا ذكر الفخر الرازي: في تفسيره الكبير حينما أمر الله لموسى الإنى باللين في مخاطبة فرعون، لوجهين:

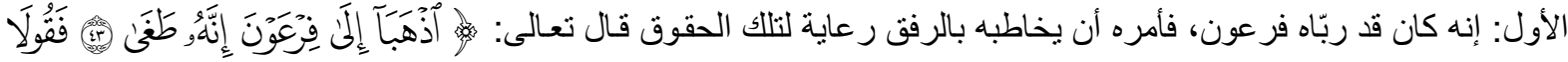
\{

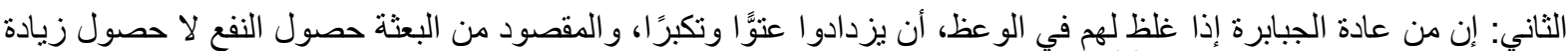

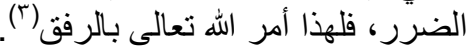

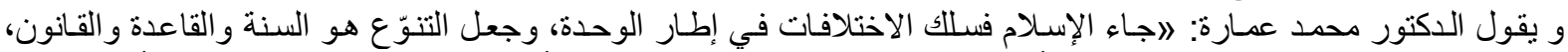

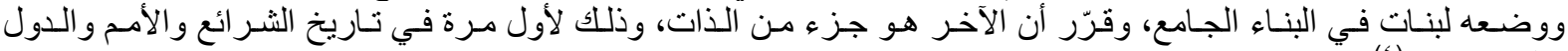

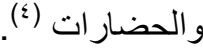

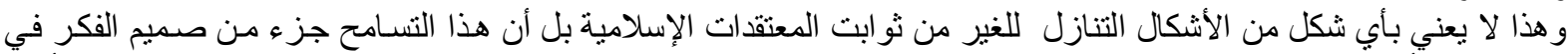

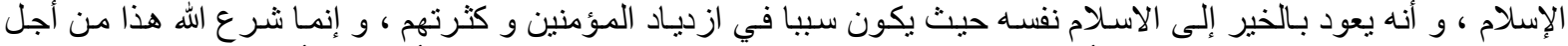

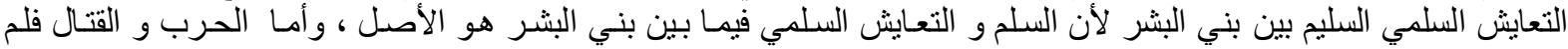

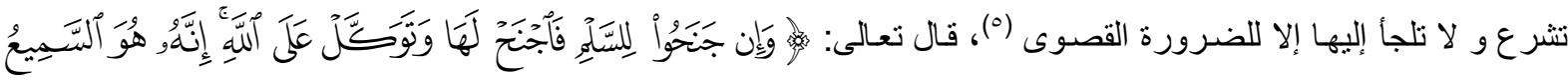

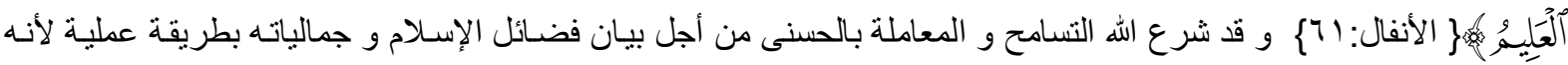

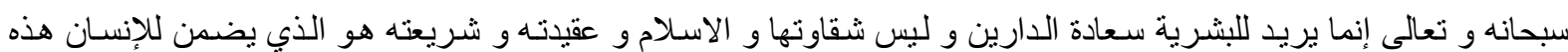
السعادة .

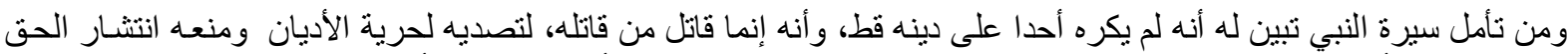

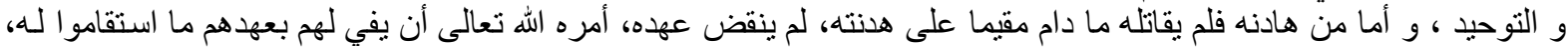

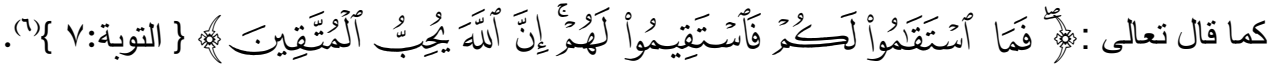

المطلب الثاني : مؤشرات التسامت في اليهودية و النصرانية التئية

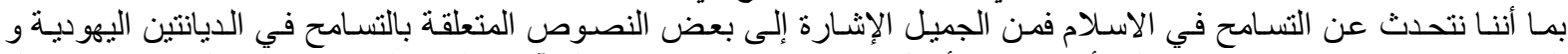

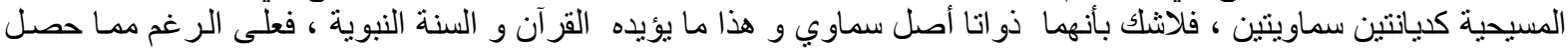

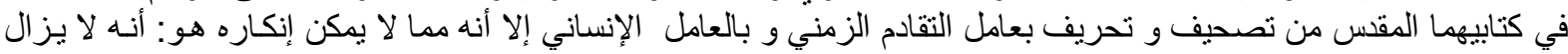

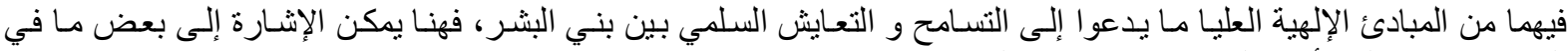

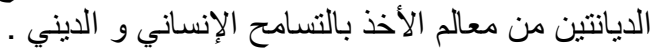

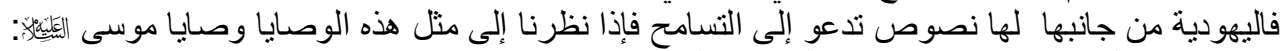

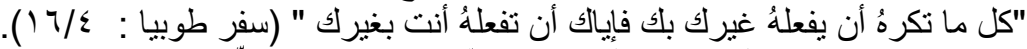

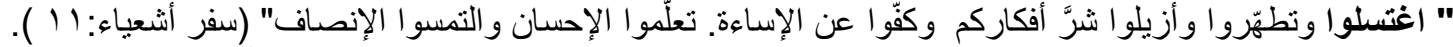

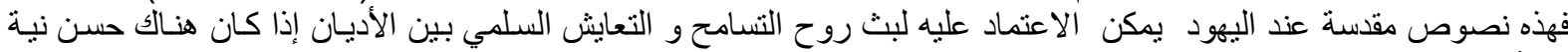
من أنباع الديانة اليهودية.

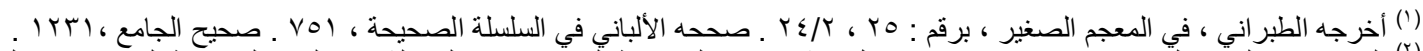

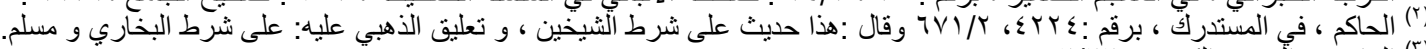

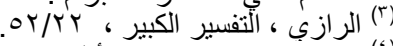

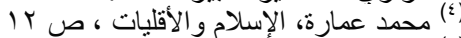

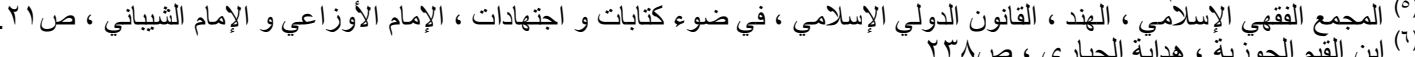


فالميحية بدور ها لها نصوص واضحة جلية للدعوة إلى التسامح ففي أناجيلها أقو ال في منتهى الصر احة في التسـامح و التعايش

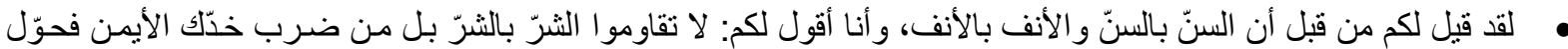

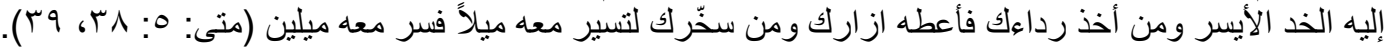

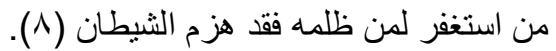

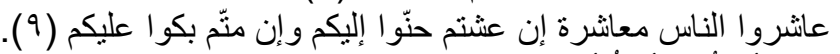

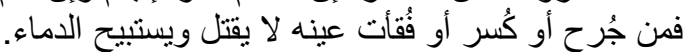

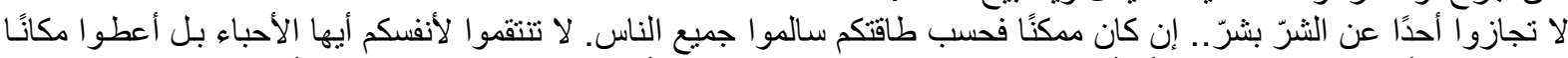

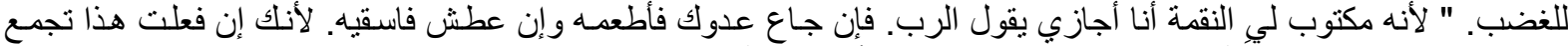

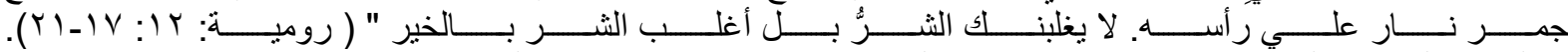

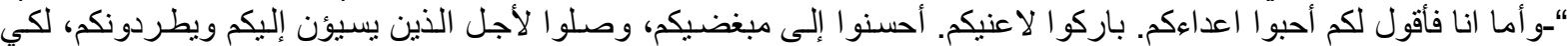

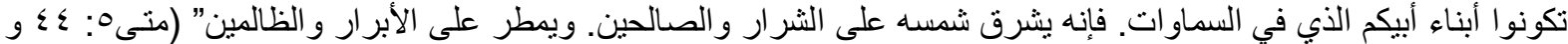

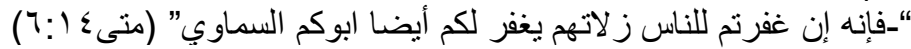

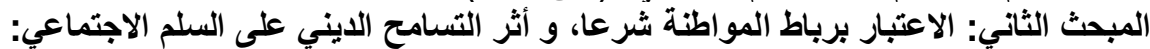

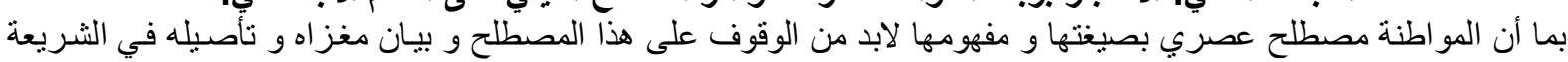

المطلب الأول : المواطنة و تأصيلها الشرعي:

الاسلامية ، ليكون القارئ على بيّنة منه.

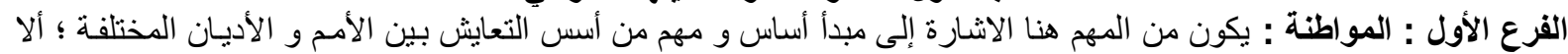

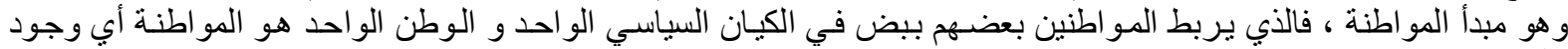

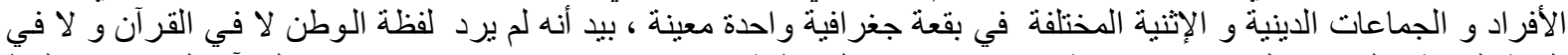

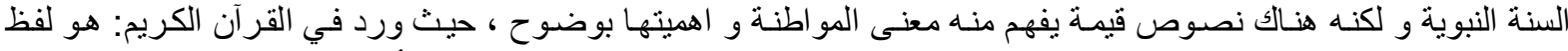

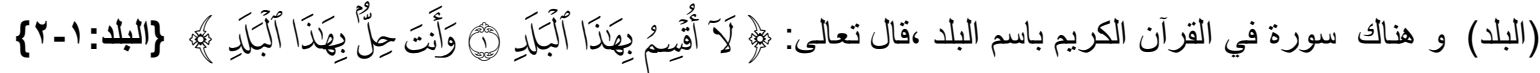

وقد ورد أيضا لفظ بلدة في قوله تعالى:

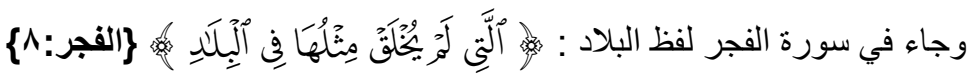

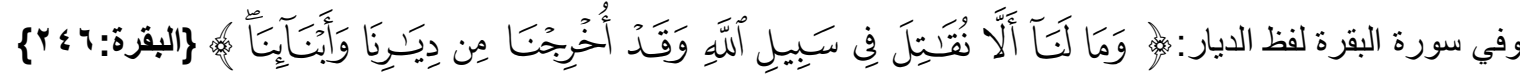

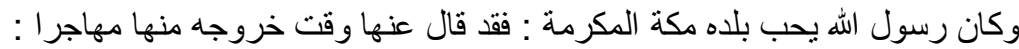

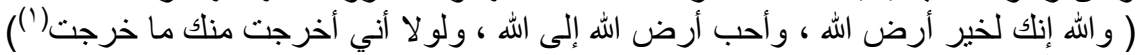

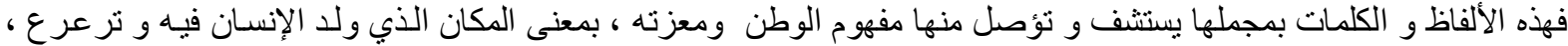

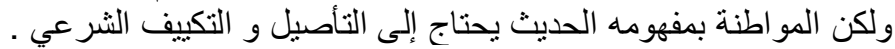
الفرع الثاني : تأصيل فكرة المواطنة بالمفهوم الإسلامي :

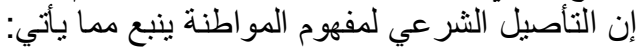

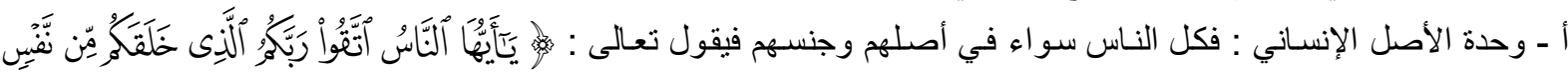

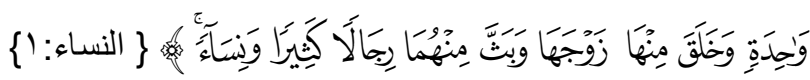

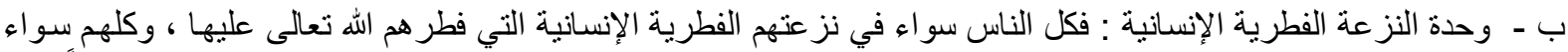

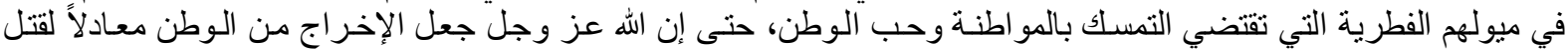

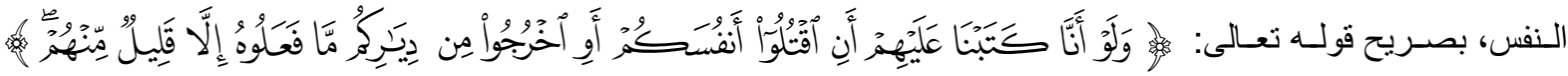
$\{77: 47$ النساء:

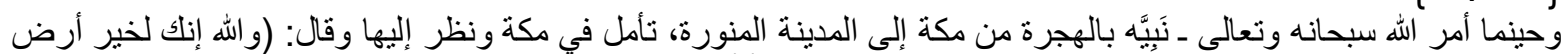

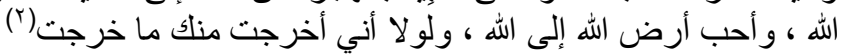

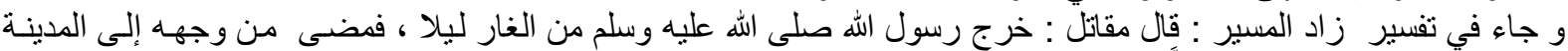

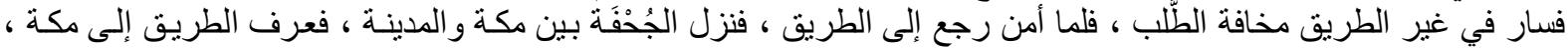

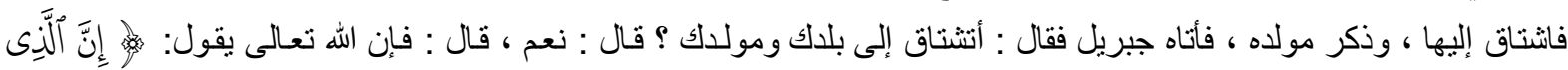

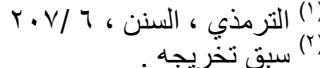




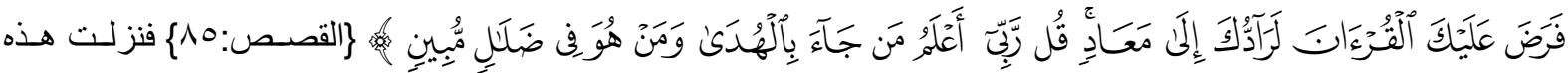

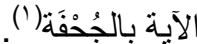

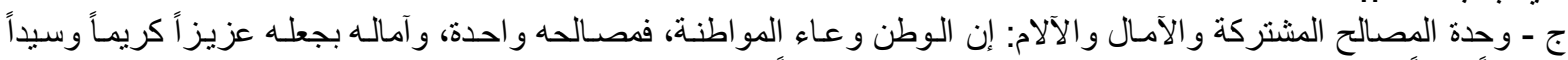

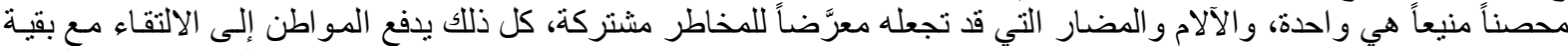

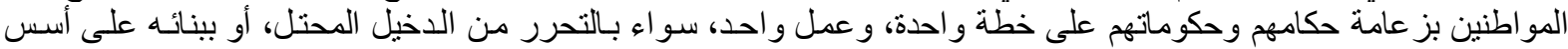

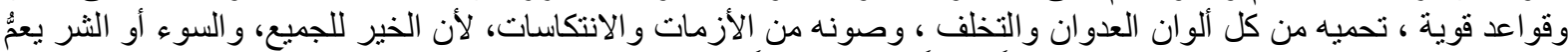

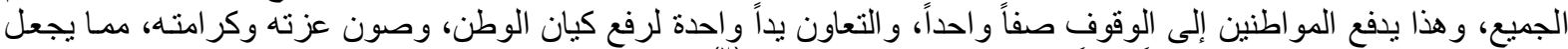

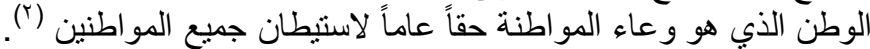

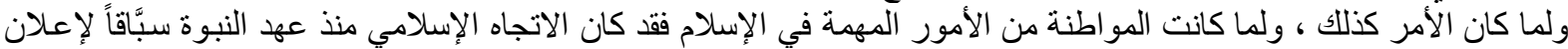

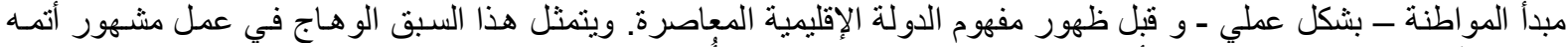

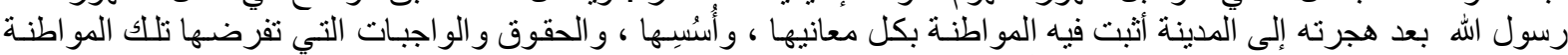

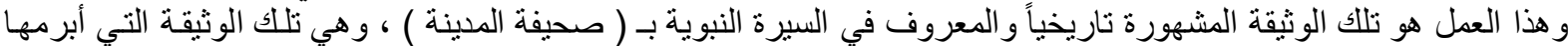

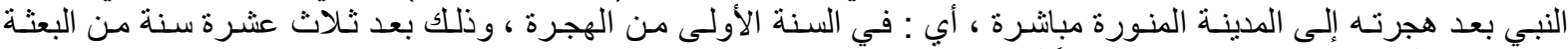
النبوية وقد أبرزت هذه الوثيه الوثقة المهمة جداً أمرين:

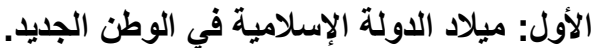

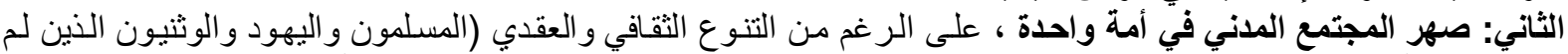

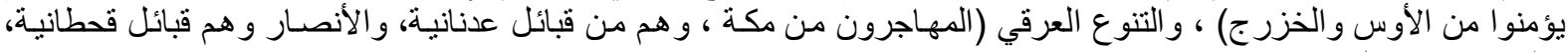

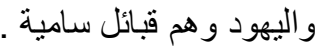
و هاهو بعض نصوص فوص الوثثية :"بسم الله الرحمن الرحيم ، هذا كتاب محمد النبي الأمي بين المؤمنين و المسلمين من قريش وأهل

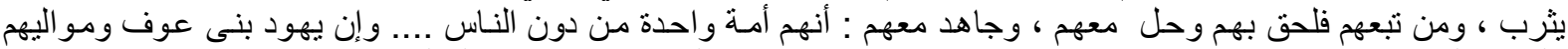

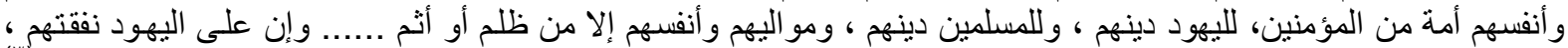

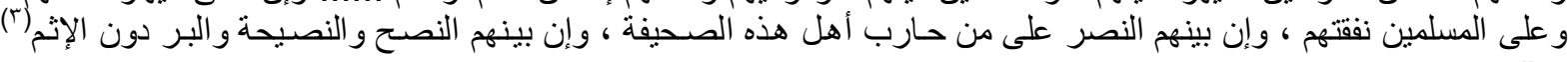

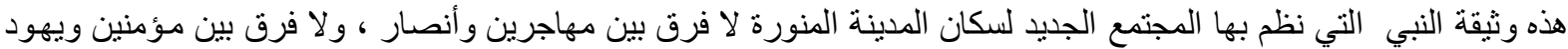

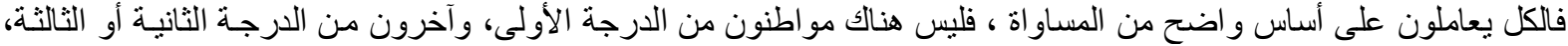

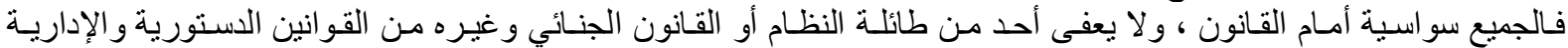
و الدولية.

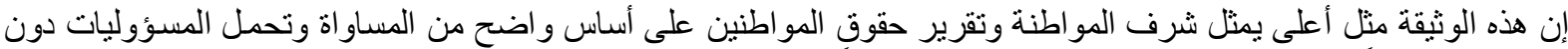

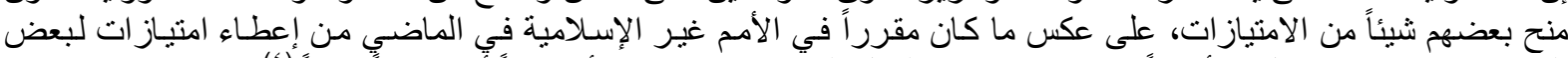

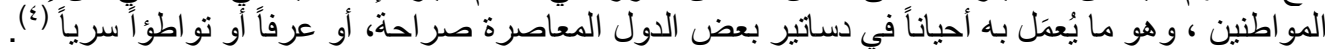

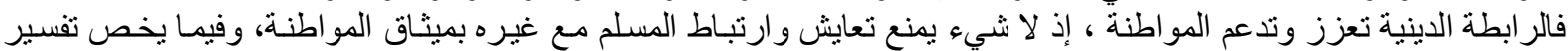

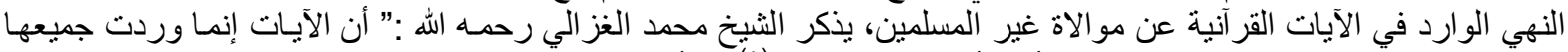

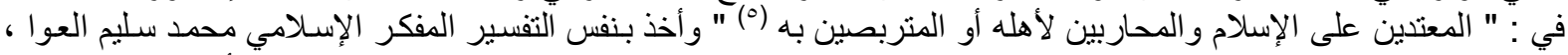

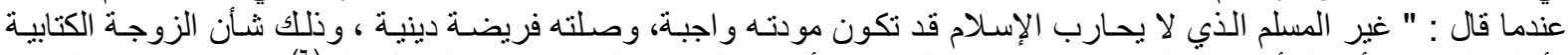

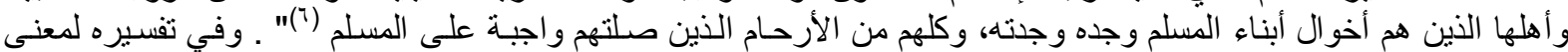

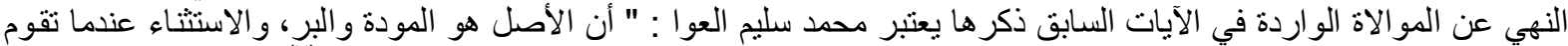

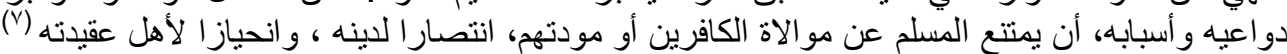

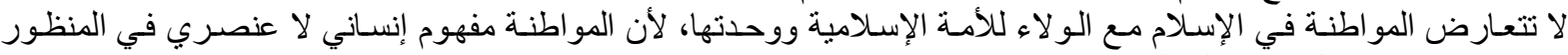
الإسلامي، و هو يشمل جميع المسلمين. ولهذا قالَ الفقهاء إن حقوق الله تعالى مبناها على المسامحة و المساهلة. وحقوق العباد مبناها على الضيق و الثـح. ويقال في الأثر

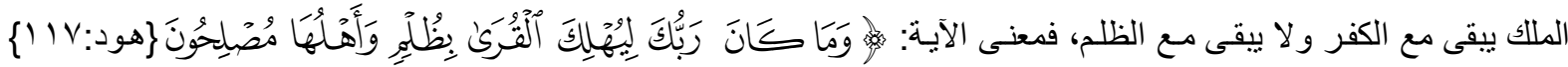

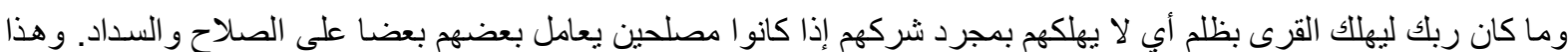

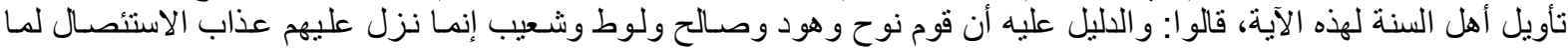
حكى الله تعالى عنهم من إيذاء الناس وظلم الخلق الخلق.

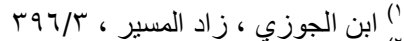

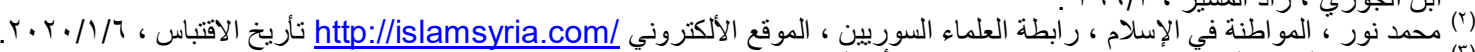

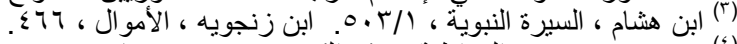

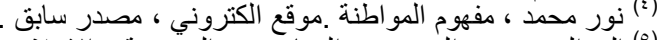

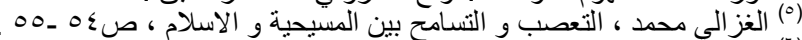

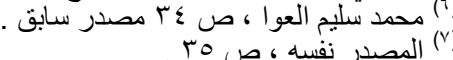


و الوجه الثاني: في التأويل وهو الذي تختاره المعتزلة هو أنه تعالى لو أهلكهم حال كونهم مصلحين لما كان متعاليا عن الظلم فلا

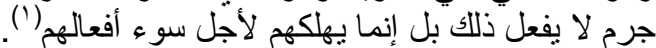

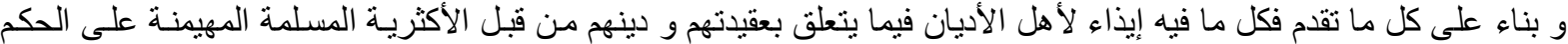

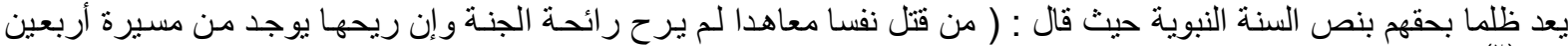
عاما(Y). و و هذا يشمل جميع الأنواع من الإيذاء.

المطلب الثاني : أثر التسامح الايني على السلم الإجتماعي:

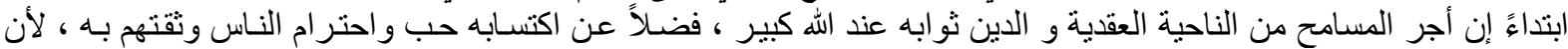

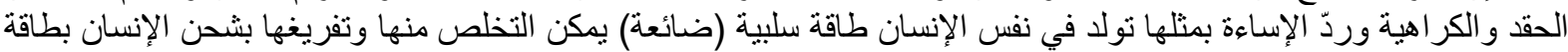

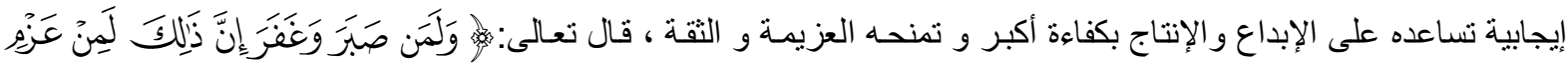

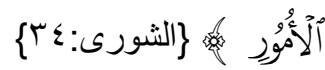

فللتسامح آثار إيجابية نكون نافعة للفرد و المجتمع لأنها تحفظ الكر امة التي منحها الله سبحانه و تعالى للإنسـان، و تعطي فرصـة

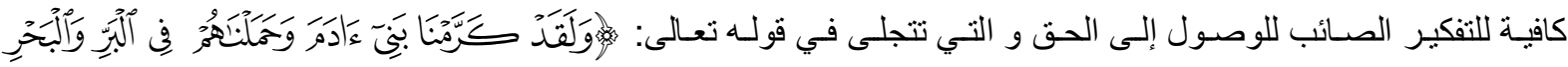

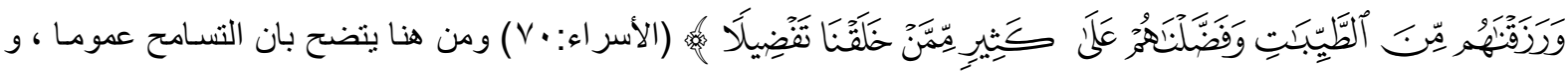

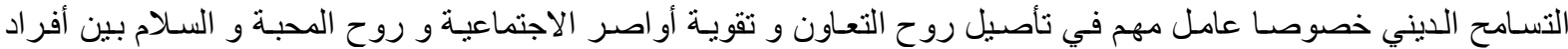

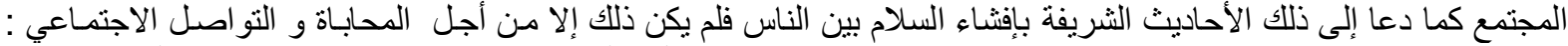

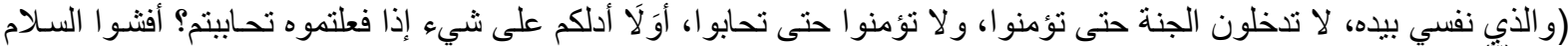

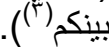

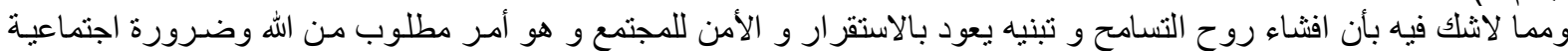

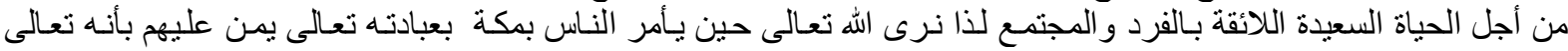

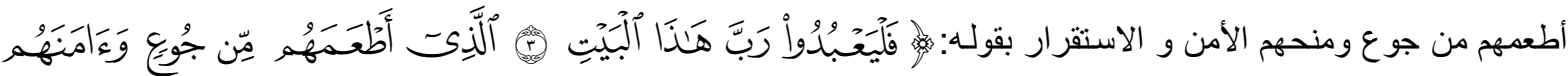

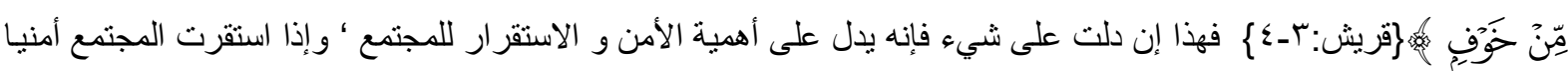

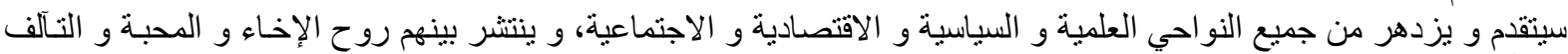

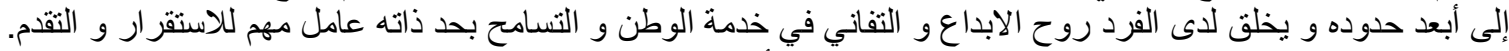

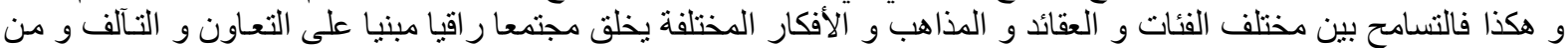

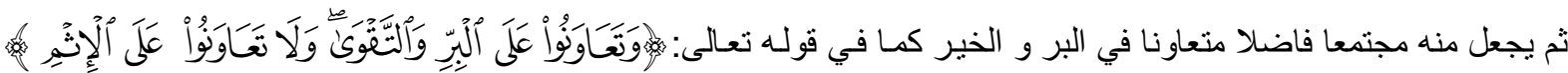

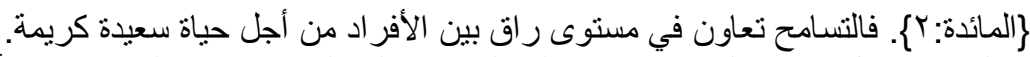

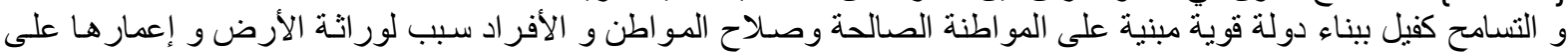

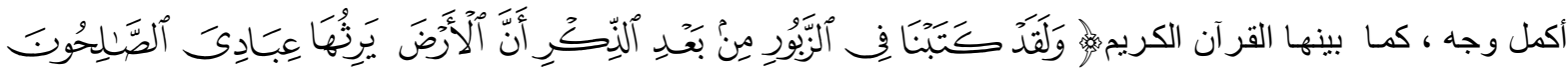

$$
\text { . }\{01: \text { : }
$$

إن التسامح بين أفر اد المجتمع و فئاته السياسية و الاثثية و أديانه طو ائفه المختلفة يعد مبداً اخلاقيا و تربويا إذا تم إجر اؤه داخل

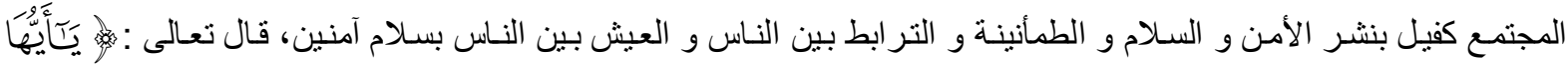

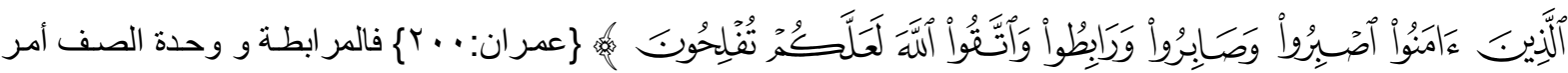

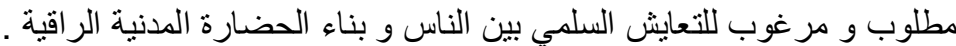

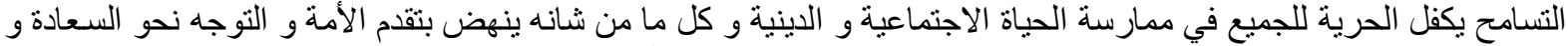

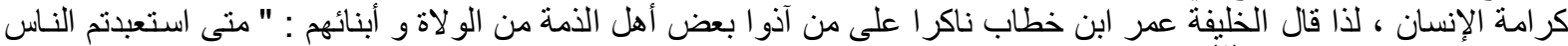

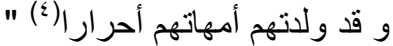

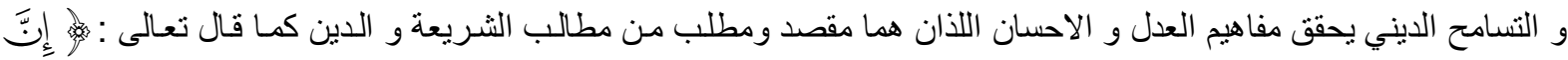

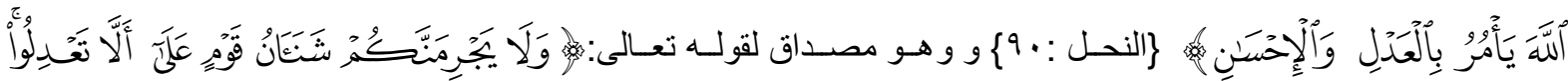

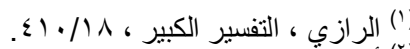

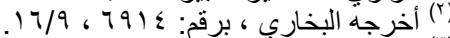

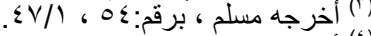

$$
\begin{aligned}
& \text { () أبو القاسم المصري ، فتوح مصر و المغرب ، } 190 .
\end{aligned}
$$




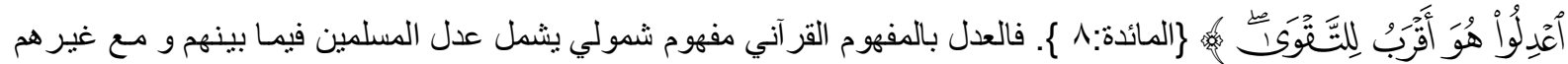

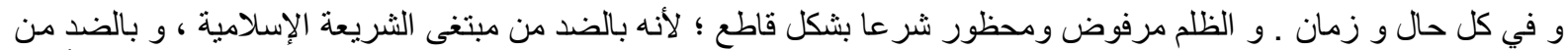

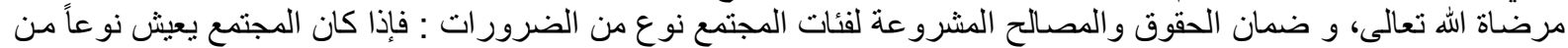

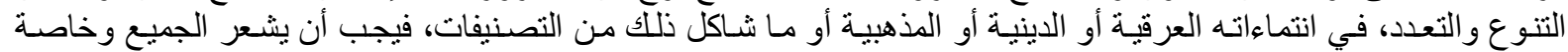

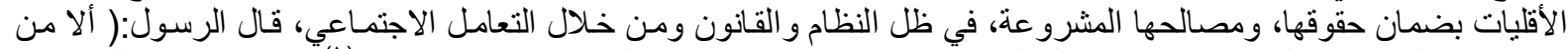

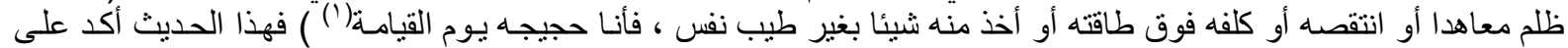
اوج عدالة الإسلام بحق من هم على غير دين الإسلام ، فها هو النبي يعلن خصومته ضد فئ من ظلم معاهدا أمسام أحكم الحساكمين

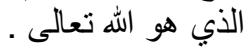

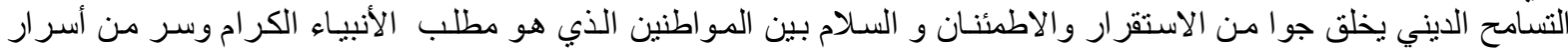

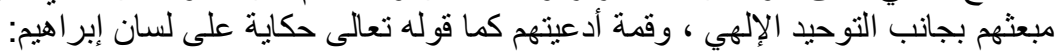

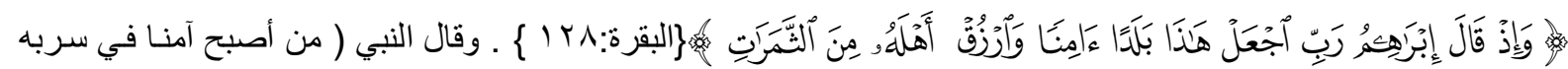

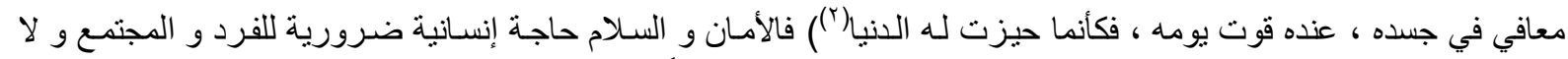

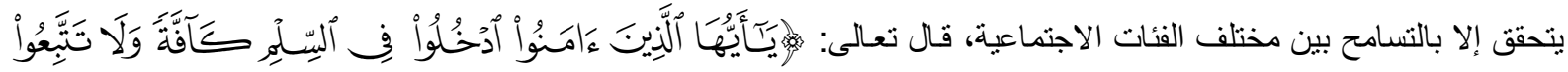

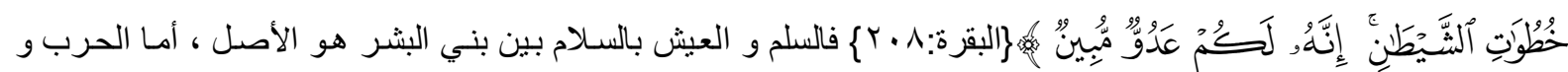
القتال فلم يشرع إلا من أجل بث الحرية الفكرية و الدينية و تطبيق العدالة و دفع الاعتداء الظالم (َ).

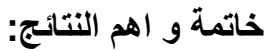

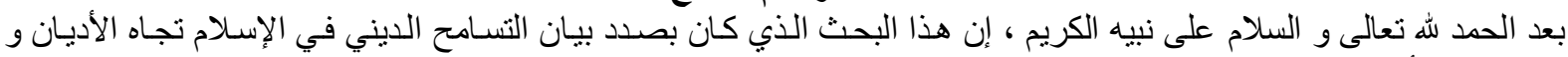
المعتقدات الأخرى التي تعيش في كنف شريعته و في ظل حكم المسلمين و التي لم تعلن و لم تجاهر بعداوة المسلمين ، بل فضلت الإن

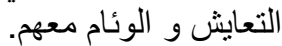

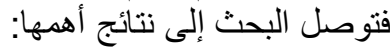
الـ إن الاختلاف في الرؤى و المعتقد و الدين سنة إلهية لم يخلو منه أب تجمع إنساني منذ بدء الخليقة و لحد آخر تجمع على وجه البسيطة .

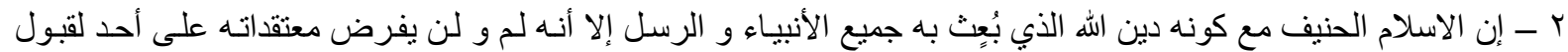

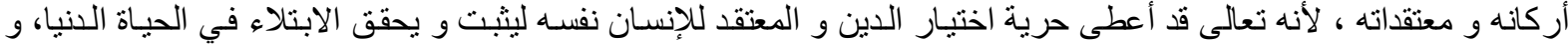

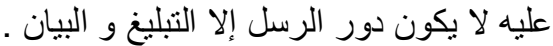

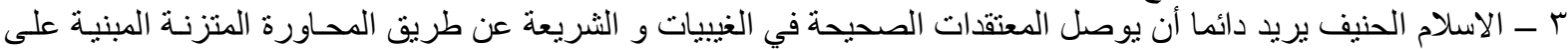

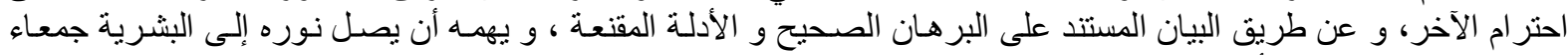

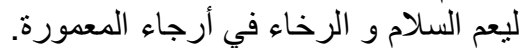

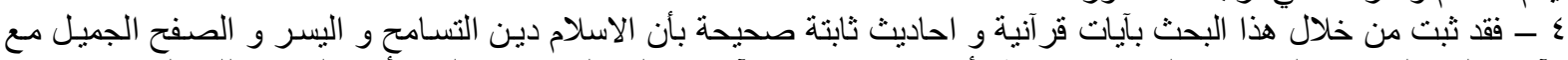

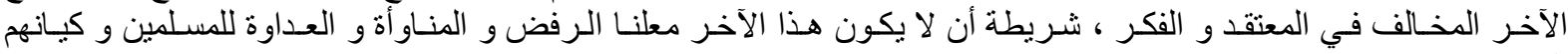
الشرعي.

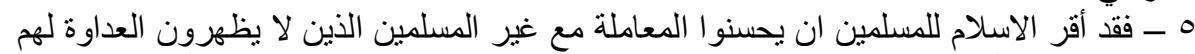

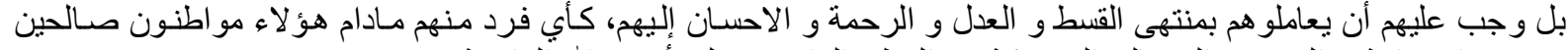

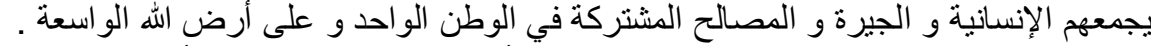

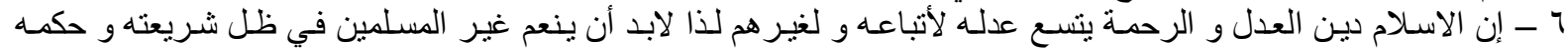

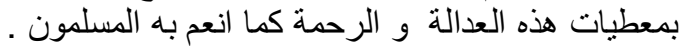

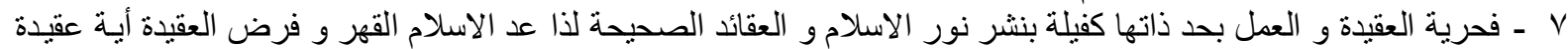

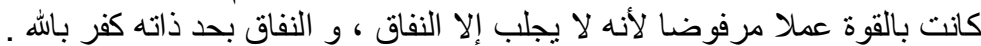

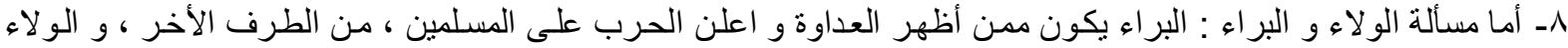

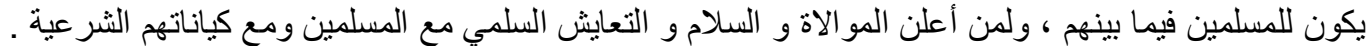

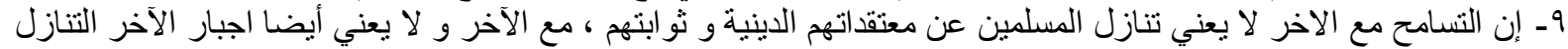

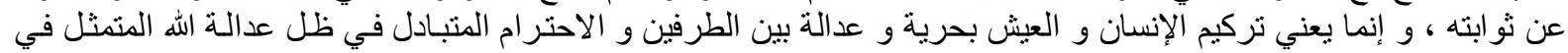
الثريعة الاسلامية.

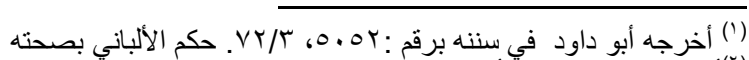

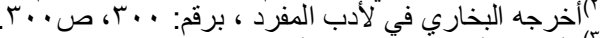

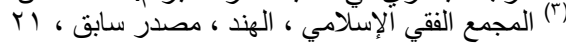




\section{قائمة المصادر و المراجع}

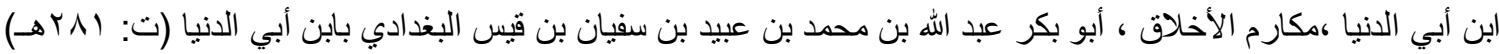

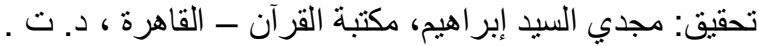

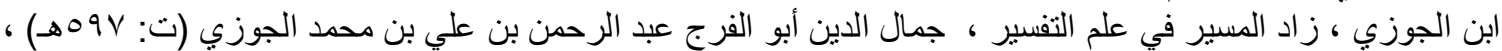

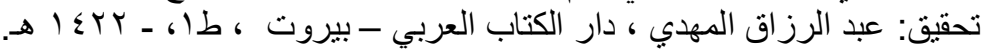

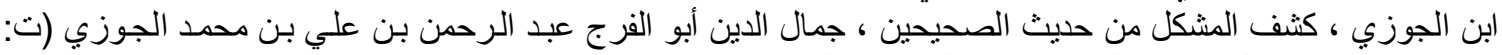

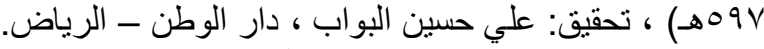

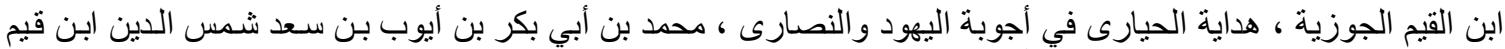

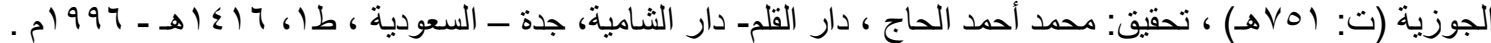

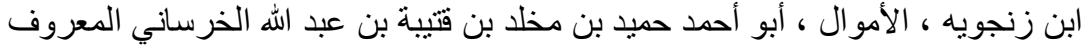

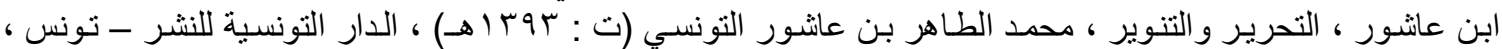
ه 19人

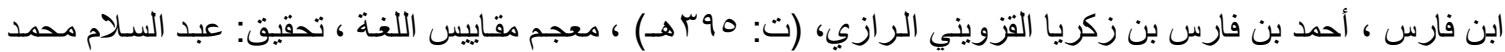

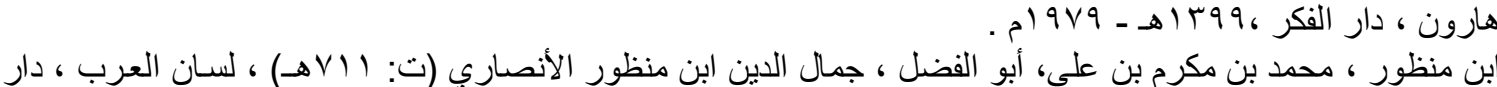

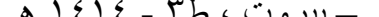

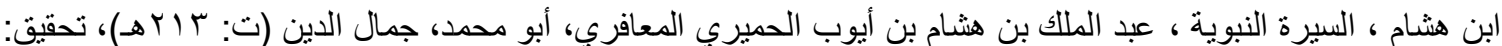

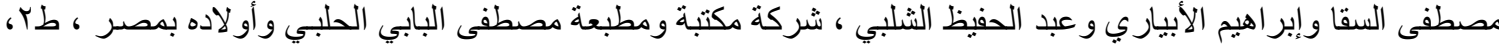
. 1900 - 1900

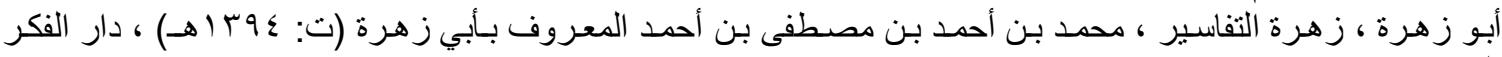

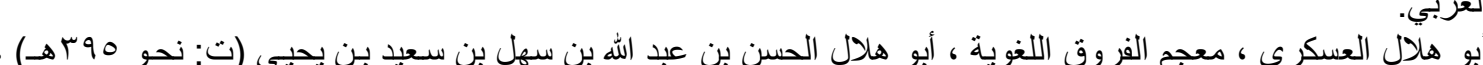

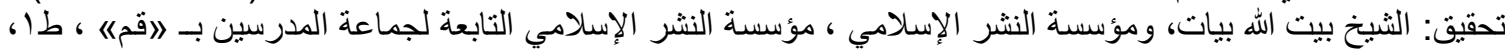
. $1 \leqslant 1 \%$

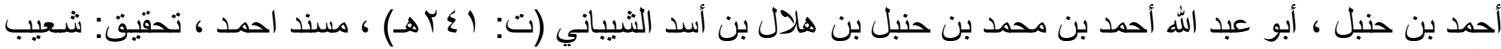

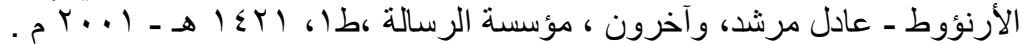

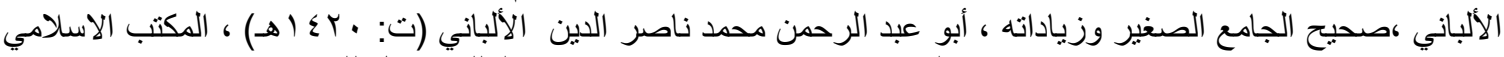

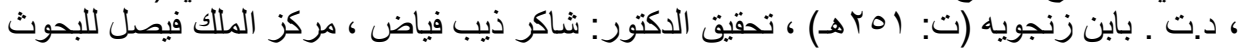

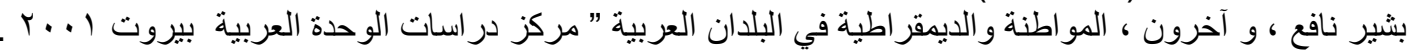

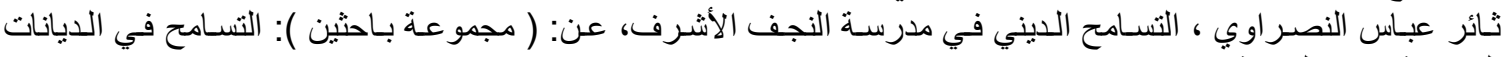

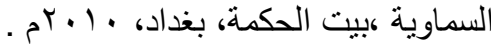

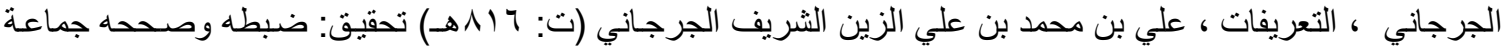

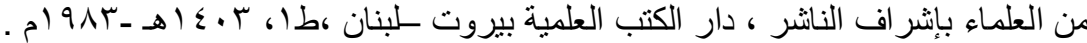

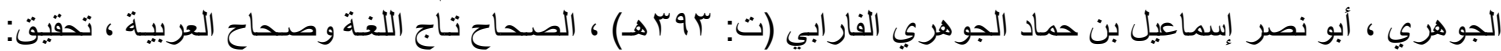

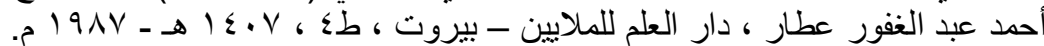

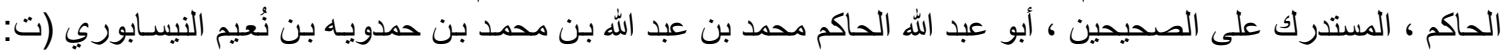

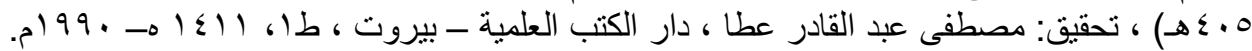

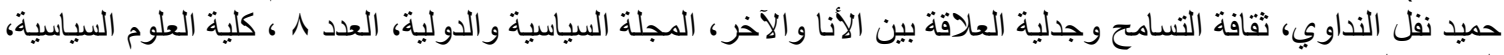

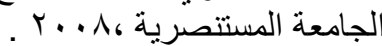

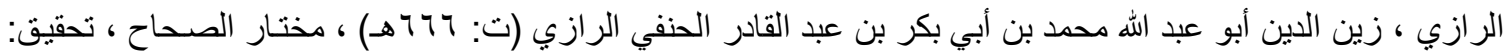

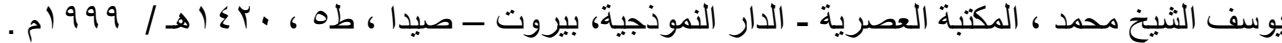

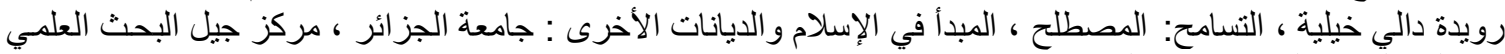

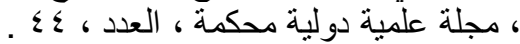

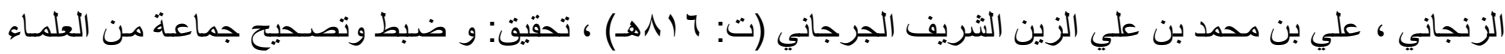

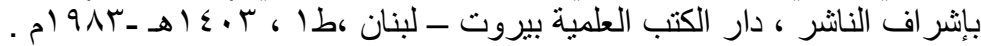

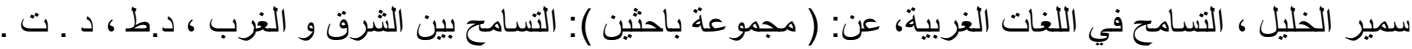

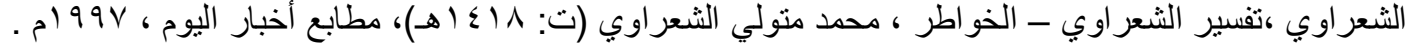

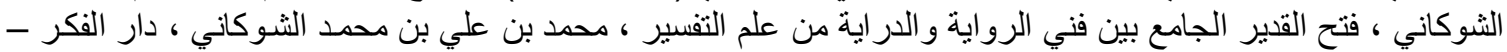

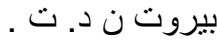
صالح بن عبد الله بن حمبذ ، نضرة النعيم في مكارم أخلاق الرسول الكريم ، تأليف عدد من المختصين باشـر اف : الشيخ 


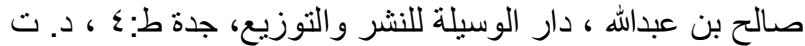
الطبر اني ، المعجم الكبير ، أبو القاسم سليمان بن أحمد الطبراني ، (ت: ـ بـ هـ ) ، تحقيق: حمدي بن عبد المجيد السلفي ،

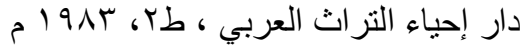

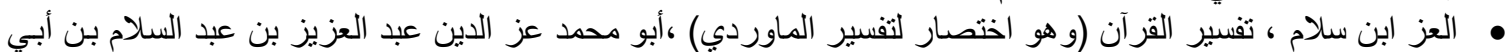

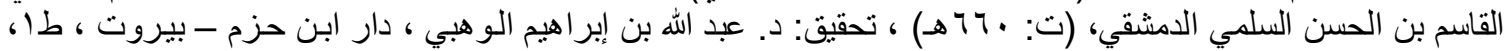

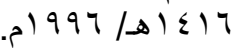

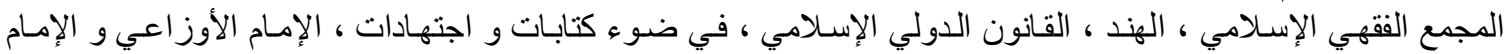

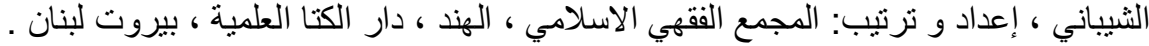

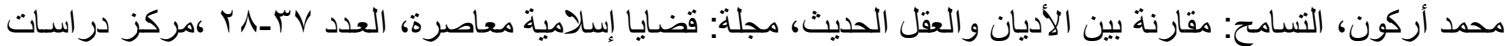

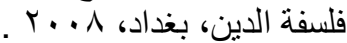

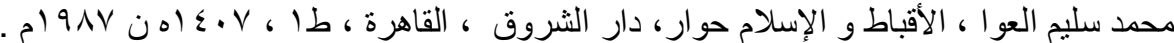

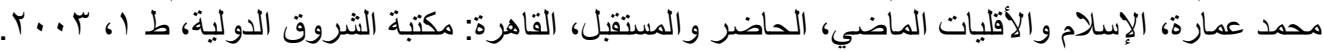

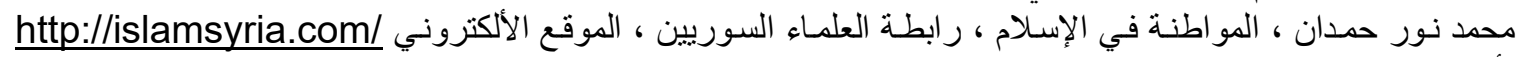

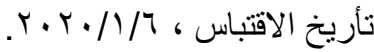

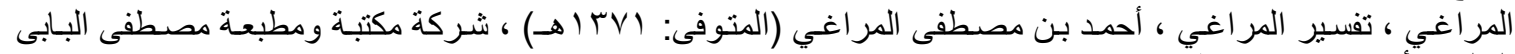

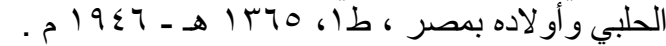

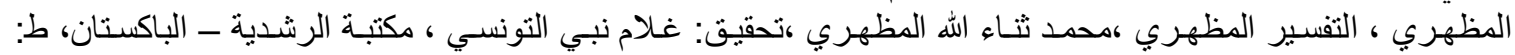
ه

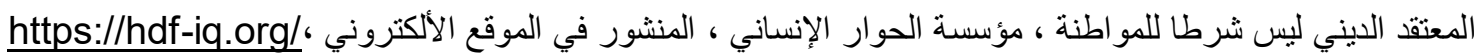

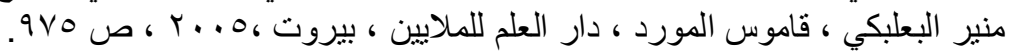

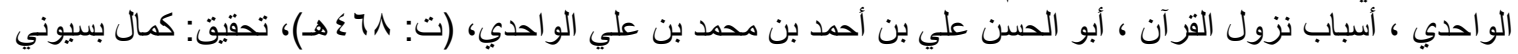

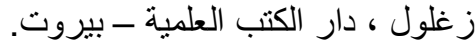

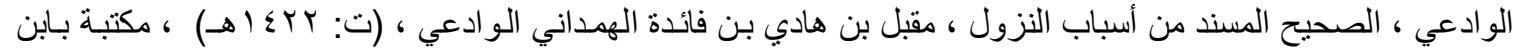

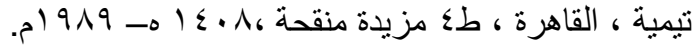

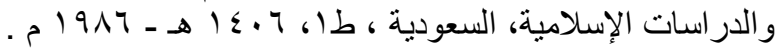
خلاصة البحث

بما أن الاسلام الحنيف عقيدة وشريعة في نفس الوقت ، فثريعته مرنة بمبادئها السامية ورؤاها البعيدة المدى ، فهي هـئه صـالحة لكل

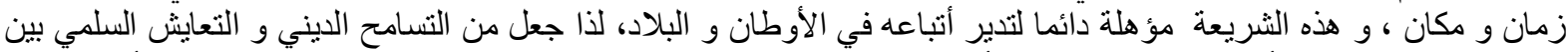

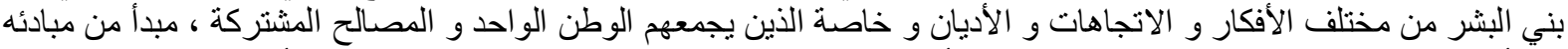

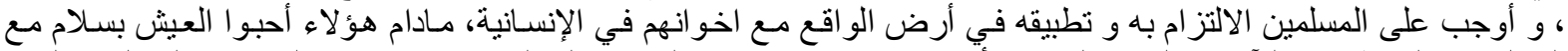

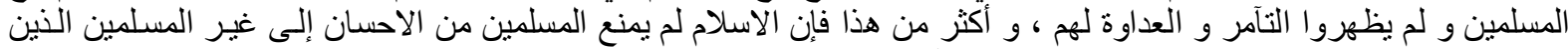

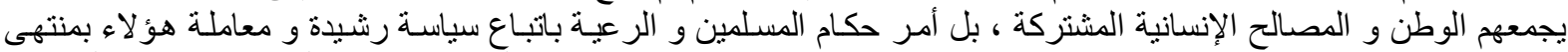

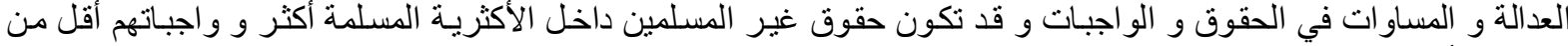




\section{Abstract}

It is well known that Islam is a belief and Sharia. Islamic Sharia is flexible and valid for all times and places. Therefore, tolerance has been made a constant principle of its high principles, and the Muslim rulers and followers of its Sharia have been obligated to adhere to it and apply tolerance with the non-Muslims in the society or country, those non-Muslims who do not show hostility to Muslims and love to live with them in the one homeland in peace and harmony. Islam does not prevent Muslims from treating people of other religions with kindness, but rather instructs them to treat them well and the rulers of Islam and the followers to treat them with justice and equality in rights and duties. As Islam orders to fulfill concluded covenants and compacts between the Muslims and the people of other religions, ideas, and doctrines best.

Keywords: Islamic Sharia, tolerance, peace. 